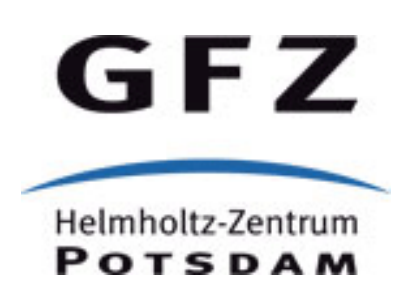

Originally published as:

Wölbern, I., Rümpker, G., Link, K., Sodoudi, F. (2012): Melt infiltration of the lower lithosphere beneath the Tanzania craton and the Albertine rift inferred from S receiver functions. - Geochemistry Geophysics Geosystems (G3), 13, Q0AK08

DOI: 10.1029/2012GC004167 


\title{
Melt infiltration of the lower lithosphere beneath the Tanzania craton and the Albertine rift inferred from $S$ receiver functions
}

\author{
Ingo Wölbern and Georg Rümpker \\ Institute of Geosciences, Goethe University Frankfurt, Altenböferallee 1, DE-60438 Frankfurt, \\ Germany (woelbern@geophysik.uni-frankfurt.de; rumpker@geophysik.uni-frankfurt.de)
}

\section{Klemens Link}

Institute of Geosciences, University of Mainz, Becherweg 21, DE-55099 Mainz, Germany (linkk@.uni-mainz.de)

\section{Forough Sodoudi \\ Helmboltz Centre Potsdam, GFZ German Research Centre for Geosciences, Telegrafenberg, DE-14473 Potsdam, Germany (foroug@gfz-potsdam.de) \\ Also at Freie Universität Berlin, Institut für Geologische Wissenschaften, Malteserstr. 74-100, DE-12249 Berlin, Germany}

[1] The transition between the lithosphere and the asthenosphere is subject to numerous contemporary studies as its nature is still poorly understood. The thickest lithosphere is associated with old cratons and platforms and it has been shown that seismic investigations may fail to image the lithosphere-asthenosphere boundary in these areas. Instead, several recent studies have proposed a mid-lithospheric discontinuity of unknown origin existing under several cratons. In this study we investigate the Tanzania craton in East Africa which is enclosed by the eastern and western branches of the East African Rift System. We present evidence from S receiver functions for two consecutive discontinuities at depths of 50-100 km and 140$200 \mathrm{~km}$, which correspond to significant S wave velocity reductions under the Tanzania craton and the Albert and Edward rift segments. By comparison with synthetic waveforms we show that the lower discontinuity coincides with the LAB exhibiting velocity reductions of 6-9\%. The shallower interface reveals a velocity drop that varies from $12 \%$ beneath the craton to $24 \%$ below the Albert-Edward rift. It is interpreted as an infiltration front marking the upper boundary of altered lithosphere due to ascending asthenospheric melts. This is corroborated by computing $\mathrm{S}$ velocity variations based on xenolith samples which exhibit a dense system of crystallized veins acting as pathways of the infiltrating melt. Mineral assemblages in these veins are rich in phlogopite and pyroxenite which can explain the reduced shear wave velocities. Melt infiltration represents a suitable mechanism to form a mid-lithospheric discontinuity within cratonic lithosphere that is underlain by anomalously hot mantle.

Components: 10,700 words, 11 figures, 1 table.

Keywords: East African Rift; Tanzania craton; lithosphere; mantle metasomatism.

Index Terms: 3621 Mineralogy and Petrology: Mantle processes (1038); 7218 Seismology: Lithosphere (1236); 8103 Tectonophysics: Continental cratons.

Received 27 March 2012; Revised 20 June 2012; Accepted 20 June 2012; Published 4 August 2012. 
Wölbern, I., G. Rümpker, K. Link, and F. Sodoudi (2012), Melt infiltration of the lower lithosphere beneath the Tanzania craton and the Albertine rift inferred from S receiver functions, Geochem. Geophys. Geosyst., 13, Q0AK08, doi:10.1029/ 2012 GC004167.

Theme: The Lithosphere-Asthenosphere Boundary

\section{Introduction}

[2] The lithosphere is commonly described as the rigid lid of the earth's mantle. It is characterized by high seismic velocities with respect to the underlying asthenosphere, which is mechanically much weaker. However, neither the cause of thickness variations of this boundary layer nor the nature of the transition to the asthenosphere are well understood [e.g., Rychert et al., 2010]. Geophysical studies show that the lithospheric thickness varies from $\sim 80 \mathrm{~km}$ under oceanic regions to $>200 \mathrm{~km}$ beneath cratons, where the lithosphere is postulated to be particularly cold and stable [e.g., Lebedev and Van Der Hilst, 2008; Rychert and Shearer, 2009; Romanowicz, 2009]. In oceanic regions, the lithosphere-asthenosphere boundary (LAB) appears as a pronounced feature at depths of $50-90 \mathrm{~km}$ [e.g., Kawakatsu et al., 2009]. Beneath continents it is observed at an average depth of about $110 \mathrm{~km}$. The LAB has been reported as a sharp boundary in areas where the lithosphere is relatively young [Ford et al., 2010; Rychert et al., 2005; Lekic et al., 2011] with a sharpness of the velocity reduction that may not be explained by increasing temperature alone. Either a small amount of partial melt or the presence of volatiles such as water is required [Fischer et al., 2010; Karato and Jung, 1998]. The underlying asthenosphere extends to depths of about $210 \mathrm{~km}$ with its bottom defined by the Lehmann discontinuity [e.g., Thybo and Perchuć, 1997].

[3] Under thick platforms and cratons the lithosphere may reach depths of more than $200 \mathrm{~km}$. These thick cratonic keels exhibit melt-depleted compositions [e.g., Miller and Eaton, 2010; Yuan and Romanowicz, 2010] while the asthenosphere is poorly developed or even absent. Seismic investigations often fail to image the lithosphere-asthenosphere boundary in such regions [e.g., Rychert and Shearer, 2009; Eaton et al., 2009]. Here, its seismic invisibility points to a slow gradual velocity decrease probably due to a purely thermal transition [Abt et al., 2010; Ford et al., 2010; Savage and Silver, 2008]. Some recent receiver-function studies have revealed a midlithospheric discontinuity with a negative impedance contrast existing between 60 and $150 \mathrm{~km}$ under several cratons [Fischer et al., 2010]. This interface is too shallow to be regarded as the LAB but the petrological origin of this additional discontinuity and its assumed distinctness from the $\mathrm{LAB}$ remain uncertain. Several processes have been hypothesized: A mid-lithospheric interface has been observed by, e.g., Savage and Silver [2008] at $150 \mathrm{~km}$ depth beneath the northeastern part of the Kalahari craton using $\mathrm{S}$ receiver functions that was interpreted to mark a change in composition. Accordingly, this boundary may reflect refertilized depleted lithosphere by basaltic melt rich in iron and volatiles possibly related to the eruption of the Karoo flood-basalt and associated magma intrusions. A mid-lithospheric velocity reduction was also detected underneath central and western Australia at a depth range between $69 \mathrm{~km}$ and $85 \mathrm{~km}$ combining results from $\mathrm{P}$ and $\mathrm{S}$ receiver functions. It was assumed to represent either a change in grain size or fabric, vertical variations in mantle composition or low-velocity melt accumulation [Ford et al., 2010]. Abt et al. [2010] have utilized $\mathrm{P}$ and $\mathrm{S}$ receiver functions as well and compared their results with velocity profiles derived from surfacewave analysis. They reported a similar discontinuity at depth between $59 \mathrm{~km}$ and $113 \mathrm{~km}$ beneath the cratonic core and certain phanerozoic regions of the United States. The authors also proposed alteration of the cratonic lithosphere by melt or the lower boundary of an ancient, highly depleted layer of the lithosphere to explain the observed interface. A possible change in anisotropic properties was suggested by Rychert and Shearer [2009] who have performed a global receiver function study of the $\mathrm{LAB}$ also including velocity profiles derived from surface-waves. S receiver functions have further revealed the existence of a mid-lithospheric discontinuity beneath the Canadian Shield [Miller and Eaton, 2010]. From its depth variations a hypothetical phase transition or a specific depth or temperature has been excluded as the origin of this interface. Instead, the authors suggest that it is caused by remnant slabs accreted during the TransHudson orogeny. In the same region Yuan and Romanowicz [2010] have detected changes in azimuthal anisotropy coinciding with the common depths of mid-lithospheric interfaces. Here, this horizon reveals strong topography while the deeper $\mathrm{LAB}$ is rather flat. They suggest that the lower layer 


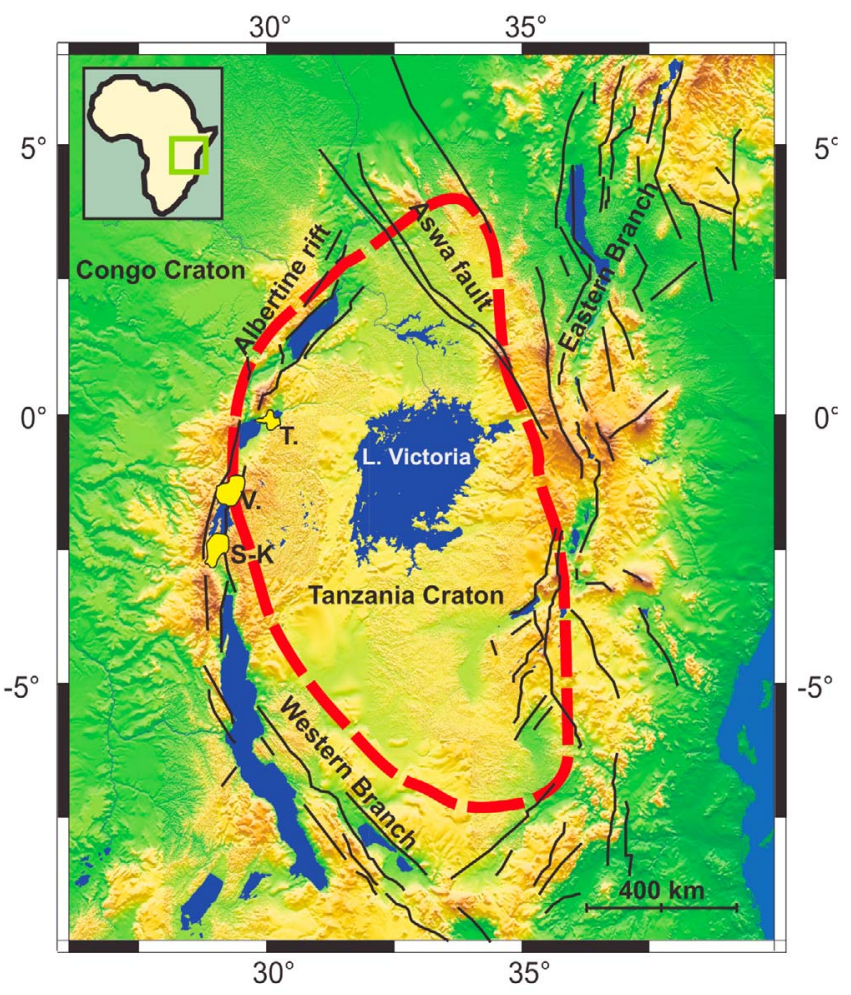

Figure 1. Topographic map of East Africa (DEM: USGS TOPO 30). Black lines mark segments of the major faults related to the eastern and western branches of the EARS and the connecting Aswa transform fault (after Milesi et al. [2004]). The outline of the Tanzania craton is given in red color according to Foley et al. [2012]. Yellow spots depict volcanic fields along the northern part of the western branch (T: Toro-Ankole, V: Virunga, S-K: South Kivu).

reflects younger, less depleted lithosphere that was probably accreted at a later stage of formation.

[4] In our study we explore the seismic properties and thickness of the lithosphere beneath the Tanzania craton and the adjacent western branch of the East African Rift System (EARS). Our aim is to map the lithosphere-asthenosphere boundary using the $\mathrm{S}$ receiver function technique and to compare the cratonic mantle lid of East Africa with the lithosphere affected by rifting. We investigate the occurrence of the mid-lithospheric discontinuity beneath the Tanzania craton and present synthetic receiver functions in order to develop a velocity model that is capable of explaining our data. The results are finally compared to a velocity model computed from bulk mineral composition of the upper mantle as constrained from $>500$ xenolith samples. Combining seismological and mineralogical information we develop a model that is able to explain these observations.

\section{The Tanzania Craton and the EARS}

[5] The East-African rift system (EARS) is a major tectonic structure traversing the eastern part of the
African continent (Figure 1). It comprises the generally north-south trending eastern and western branches each stretching across distances of $>2000 \mathrm{~km}$ [Chorowicz, 2005]. These branches encircle the Archean Tanzania craton which defines the Victoria micro-plate [Calais et al., 2006]. Disregarding its northwestern edge, where the northern tip of the western branch hits Archaean cratonic lithosphere [Link et al., 2010], it is juxtaposed to mobile belts of Proterozoic age [De Waele et al., 2008; Nyblade and Brazier, 2002]. Rifting in East Africa probably originated in the Afar region when a mantle plume impinged on the lithosphere about $30 \mathrm{Ma}$ ago [e.g., Ebinger et al., 1989; Ebinger and Sleep, 1998]. From the Afar, the rifting process propagated southward until it reached the Tanzania craton. The opening of the western branch may have been triggered by stress transmission across the rigid craton [Nyblade and Brazier, 2002]. A recent tomographic study, instead, indicates that two distinct mantle plumes may be located beneath East Africa, one being located beneath the Afar region and a smaller one beneath the eastern branch of the EARS, east of Lake Victoria [Montelli et al., 2006]. This observation 
agrees with results from a receiver-function study that indicates a depression of the $410-\mathrm{km}$ discontinuity beneath northern Tanzania. Such offset probably results from a positive temperature anomaly due to plume material spreading out westward under the cratonic lithosphere [Nyblade et al., 2000]. This interpretation is further supported by the rather shallow cratonic root. In contrast, a recent study of the volcanism in the Afar Rift has revealed that plume influence nowadays only plays a minor role and that the plume signature has faded in the past [Rychert et al., 2012].

[6] Among the African cratons and platforms the Tanzania craton is reported to exhibit the least developed cratonic keel. Previous estimates of its lithospheric thickness have been obtained from different studies and vary by some tens of kilometers: Weeraratne et al. [2003] have derived a thickness of about $170 \mathrm{~km}$ from Rayleigh wave tomography, while Ritsema et al. [1998] and Ebinger and Sleep [1998] proposed a minimum extension of the mantle lid down to $200 \mathrm{~km}$ from $\mathrm{P}$ wave tomographic inversion. Fishwick [2010] determined a lithospheric thickness of 150$160 \mathrm{~km}$ from surface wave tomography beneath Tanzania compared to about $200 \mathrm{~km}$ beneath the Kalahari craton and $>225 \mathrm{~km}$ beneath the Congo craton, respectively. Surface waves have also been used by Sebai et al. [2006]. According to their tomographic study the Tanzania craton extends down to $180 \mathrm{~km}$ depth while the Congo, WestAfrica and Kalahari cratons reach about $300 \mathrm{~km}$. Finally, Begg et al. [2009] found a rather shallow lithosphere-asthenosphere boundary at $150 \mathrm{~km}$ depth beneath Tanzania compared to the other cratons throughout Africa. The depth to the LAB has also been determined beneath the eastern branch of the EARS from travel-time tomography with rather low resolution at a depth between 35 and $65 \mathrm{~km}$ west of Lake Victoria where the lithosphere is underlain by a pronounced low-velocity layer [Green et al., 1991]. In contrast, a minimum thickness of $75 \mathrm{~km}$ has been derived for the same area from basalt chemistry [le Roux et al., 2001]. In a recent study combining receiver functions and Rayleigh wave group velocities a lithospheric thickness of 70-80 km has been found beneath the Ethiopian Plateau [Dugda et al., 2007]. For the western branch, so far, no comparable geophysical study has been carried out. Geochemical data, however, suggest lateral variations of mantle composition and lithospheric thickness [Furman and Graham, 1999; Chakrabarti et al., 2009]. Petrological studies indicate a thickened pre-rift lithosphere $(>100 \mathrm{~km})$ for the northernmost tip of the western branch [Link et al., 2010].

\section{S Receiver Functions}

\subsection{Data and Processing}

[7] We apply the $\mathrm{S}$ receiver function technique to study the thickness of the lithosphere. This method utilizes S-to-P converted phases (Sp) that are generated at seismic discontinuities such as the LAB. S receiver functions have first been introduced as a way to isolate Sp phases by Farra and Vinnik [2000]. Since then the method has been improved and is nowadays used as a standard tool especially to map the LAB [e.g., Kumar et al., 2005; Yuan et al., 2006; Sodoudi et al., 2009]. When an incident shear wave passes through a seismic discontinuity part of its energy transforms into a compressional $\mathrm{P}$ wave. This S-to-P converted phase travels at higher velocity than the parent $S$ wave and, therefore, arrives as a precursor at a specific station. For this reason, $\mathrm{S}$ receiver functions are free of multiple phases in contrast to $\mathrm{P}$ receiver functions. The difference in arrival times serves as a measure for the depth of the converting interface. $\mathrm{P}, \mathrm{S}_{\mathrm{V}}$ and $\mathrm{S}_{\mathrm{H}}$ fractions of the wavefield are separated by rotating the recorded $\mathrm{Z}, \mathrm{N}, \mathrm{E}$ components into a local ray-coordinate system. We first use the theoretical back azimuth for rotation into the Z, R, T system. In a second step we rotate by incident angle in order to obtain L,Q,T components. Incident angles are selected by minimizing the $\mathrm{S}$ wave energy and simultaneously maximizing the amplitude of the converted signal on the L component which almost exclusively contains compressional energy after rotation. The source function and path effects are removed from the signal by deconvolving the waveform of the direct $S$ wave from the rotated $\mathrm{L}$ component ( $\mathrm{P}$ wave) reducing it to a spike-like impulse. Depending on epicentral distance and source depth S arrivals may overlap with other strong phases such as SKS, SKKS or ScS. In order to avoid interference the time window used for the deconvolution process is customized. Finally, the time axis is reversed to make the obtained traces comparable to customary $\mathrm{P}$ receiver functions.

[8] We compute $\mathrm{S}$ receiver functions from $\mathrm{S}$ and SKS arrivals that were recorded during a temporary seismological experiment carried out between April 2006 and October 2007. During this period a seismic network was operated in the Rwenzori region, western Uganda, within the scope of the RiftLink research group [Wölbern et al., 2010a]. 


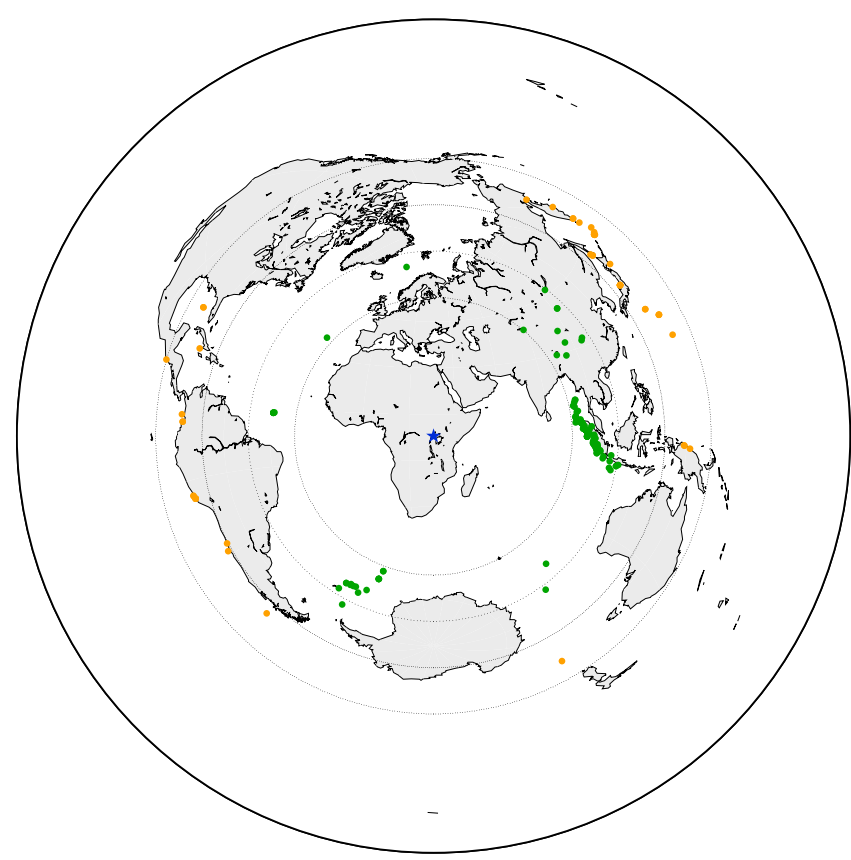

Figure 2. Distribution of events used in this study. The circles indicate epicentral distances of $60,80,100$ and 120 degrees. The green and orange dots mark epicenters contributing with S and SKS phases, respectively. The blue asterisk in the center of the map shows the location of our network.

Our temporary network consisted of 23 mobile short-period and broadband stations set up directly east of the Congo border. Additional data from the permanent station MBAR have been integrated in our analysis. The distribution of the stations used in this study is shown in Figures $5 \mathrm{~g}$ and $5 \mathrm{~h}$. Inclusion of both, S and SKS arrivals considerably increases the data coverage due to the different ranges of incidence angles. We selected teleseismic events of magnitude $\geq 5.7$ which occurred at epicentral distances between 60 and $85^{\circ}$ and $80-115^{\circ}$ for S and SKS phases, respectively. In total, we obtained 195 receiver functions, 147 from $\mathrm{S}$ phases and 48 from SKS phases, respectively. Figure 2 displays the distribution of the related epicenters. Data were examined with different filter ranges to better distinguish between coherent arrivals generated at seismic discontinuities and incoherent noise effects. Receiver functions used for stacking (Figures 5a-5d) were analyzed using a Butterworth low-pass filter with a corner frequency of $0.25 \mathrm{~Hz}$. The lateral resolution of our data can be estimated from the $\lambda / 4$-Fresnel-zone of the S-to-P converted waves [Brühl et al., 1996]. We determine a diameter of about $116 \mathrm{~km}$ at $200 \mathrm{~km}$ depth, $97 \mathrm{~km}$ at $140 \mathrm{~km}$ depth and roughly $65 \mathrm{~km}$ at $60 \mathrm{~km}$ depth. Modeling (Figures 6-9) was performed at a lower corner frequency of $0.14 \mathrm{~Hz}$ in order to focus on large scale variations. This increases the diameter of the Fresnel zone to $155 \mathrm{~km}, 130 \mathrm{~km}$ and $88 \mathrm{~km}$ at depth of $200 \mathrm{~km}, 140 \mathrm{~km}$ and $60 \mathrm{~km}$, respectively. The vertical resolution is in the order of 8-12 km.

[9] To enhance the signal-to-noise ratio for the converted phases it is necessary to stack data from several stations and events. Before stacking a moveout correction is applied to account for varying arrival times which are dependent on epicentral distance. In the light of the tectonic setting, juxtaposing cratonic and rifted lithosphere, strong depth variations of the discontinuities in the lithospheric mantle must be considered. Consequently, traces arriving from diverse back azimuths are expected to sample a specific interface at different depths due to its topography. This is expressed in varying arrival times in the receiver functions as illustrated in Figure 3 by means of data recorded at a single station. If these variations are not considered, the converted signal will not stack coherently and may even be canceled out. This effect has commonly been disregarded in previous receiver function studies as topographic variations are usually expected to be small, however, it cannot be neglected in our study due to the strong topography of the lithosphere beneath East Africa. Thus it is essential to accurately estimate the position of the piercing points for the discontinuity in question. For this purpose we determine arrival times from individual traces and calculate the corresponding conversion depth. This calculation 
(a) BAZ range: $0^{\circ}-100^{\circ}$

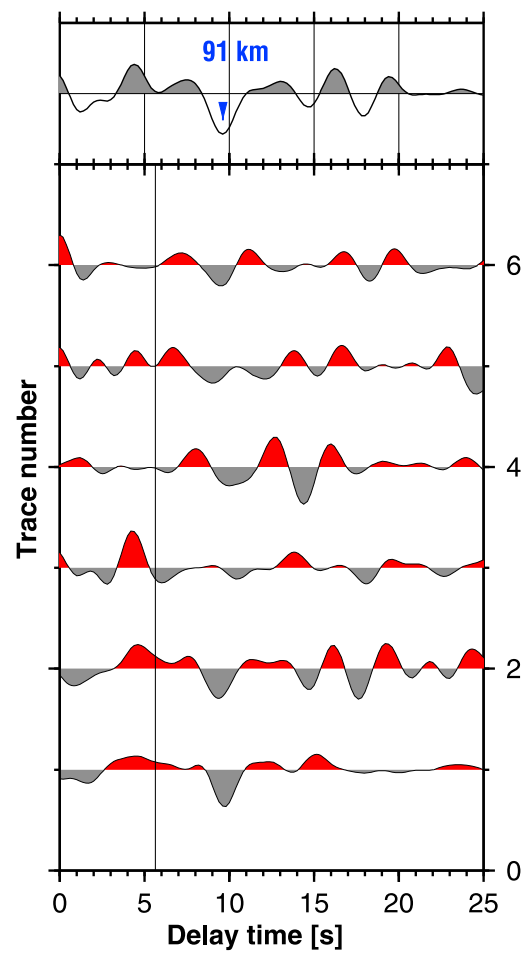

(b) BAZ range: $200^{\circ}-300^{\circ}$

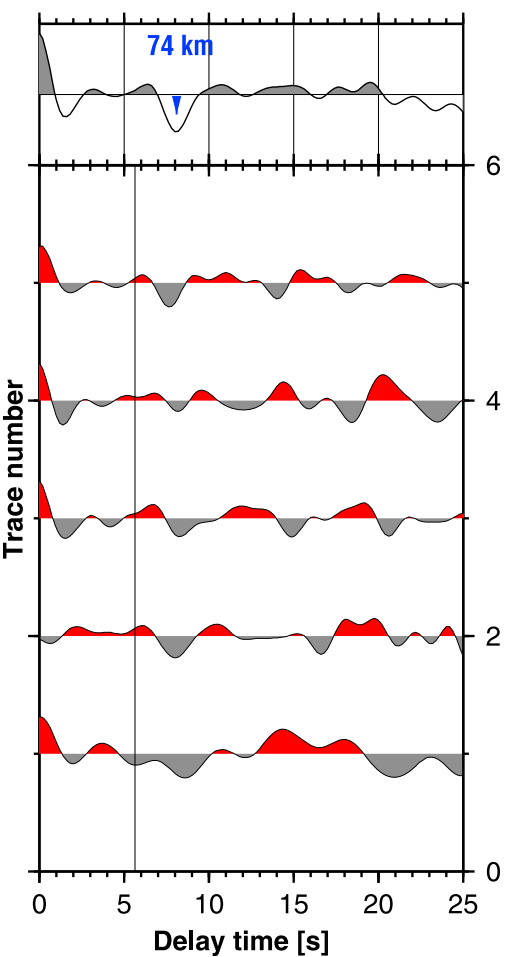

(c) BAZ range: $0^{\circ}-360^{\circ}$

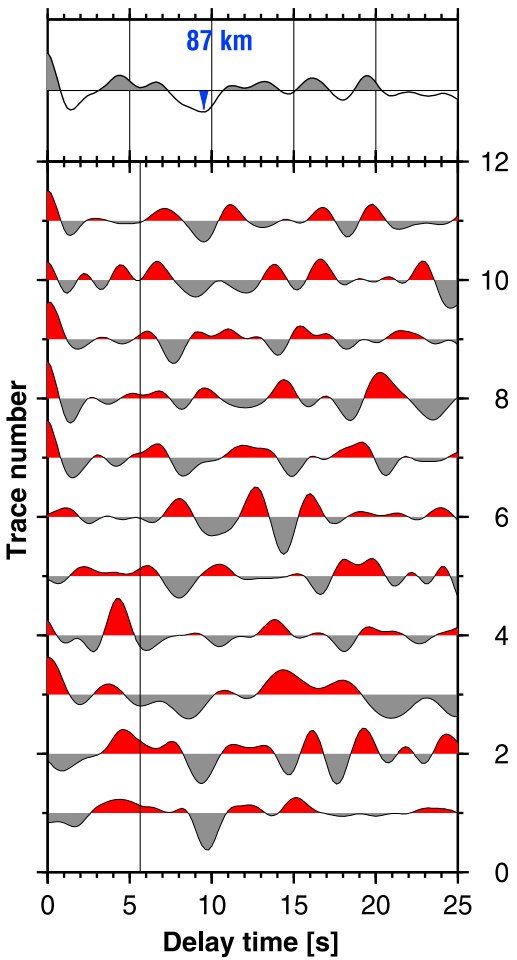

Figure 3. Data example from a single station illustrating the effect of varying arrival times due to topography of an interface sampled at different back azimuths. (a) This figure displays single receiver functions arriving from northern to eastern directions while (b) traces in this figure cover western directions. (c) This figure merges all back azimuth ranges. Stacked traces are shown on top of each section and clearly reveal different arrival times and corresponding depths. The stacking procedure in our final analysis is therefore based on regional bins, as shown in Figure 5. Data in this example are filtered with a bandpass $2 \mathrm{~s}-20 \mathrm{~s}$.

is based on a hybrid velocity model (Figure 4) derived from regional earthquakes [Bram, 1975] for the upper $125 \mathrm{~km}$ and on the IASP91 model [Kennett and Engdahl, 1991] for depths below $125 \mathrm{~km}$. We use the resulting model to compute approximate coordinates of the piercing points for each converted phase. Finally, individual receiver functions are stacked according to regional bins (Figure 5). Binning was performed separately for different discontinuities to account for the correct position of the related piercing points.

[10] Although the usage of a 1-D velocity model may seem problematic in the context of the strong depth variations the obtained accuracy of the piercing-point distribution is still acceptable: tests with different $1-D$ velocity models have shown that the coordinates of the related piercing points deviate by only a few kilometers for the majority of the raypaths. Deviations increase with distance from the station network and also with depth, but, even for a conversion depth of $200 \mathrm{~km}$ the offsets for different velocity models do not exceed $20 \mathrm{~km}$ which is small compared to the width of the Fresnel zone and thus negligible. However, an improved resolution of the lithospheric structure might be achieved in future times when better velocity models become available. To test for the robustness of the observed phases we have applied the bootstrap method [Press et al., 1992]: a random 20\% of the traces in each bin are replaced by other traces randomly selected from the same bin so that the original number of traces is obtained. In this way 20 subsets are randomly created for each bin that are used to calculate the standard deviation for each sum trace. $2 \sigma$ intervals are displayed for each stack in Figures $5 \mathrm{a}-5 \mathrm{~d}$ to illustrate the reliability of the sum traces obtained from the original data set in each bin.

\subsection{Observations}

[11] We focus on the lithosphere-asthenosphere boundary which involves decreasing velocities with depth and should appear as a signal of negative amplitude. Receiver functions in Figure 5 show two 


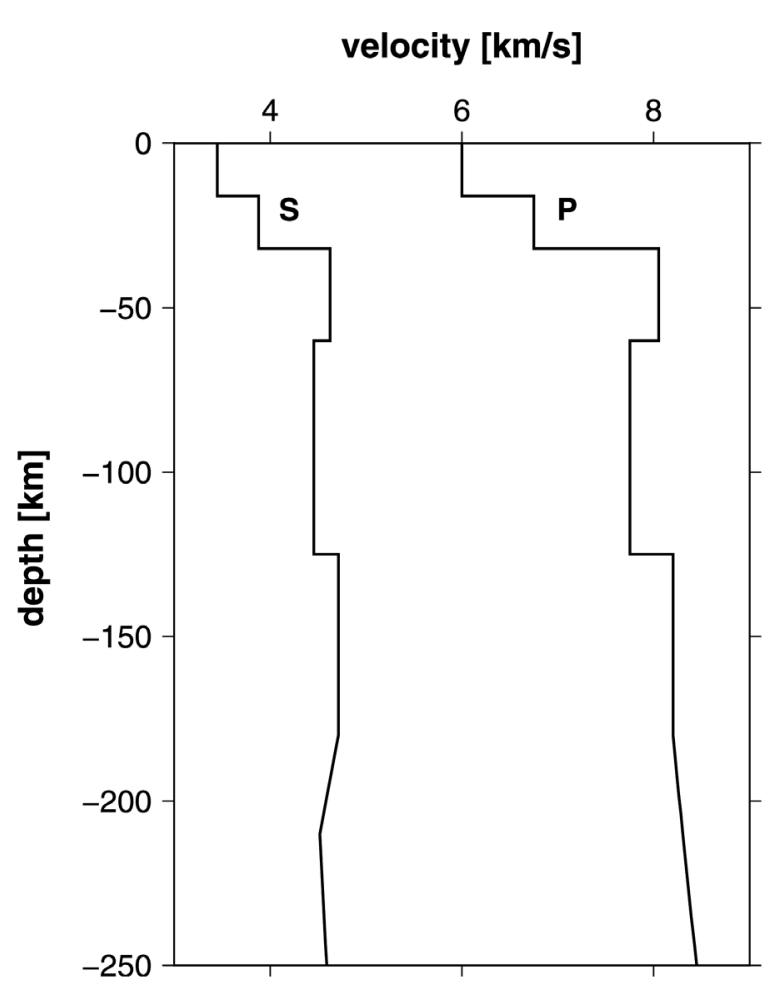

Figure 4. Velocity model used to determine conversion depths from arrival times in the individual traces. The upper $125 \mathrm{~km}$ are identical to the UVI-N74 model [Bram, 1975]. Below, velocities of IASP91 earth reference model have been assumed [Kennett and Engdahl, 1991].

consecutive negative signals. The first occurs at delay times ranging from 6 to $11 \mathrm{~s}$ (Figures 5a and 5c) roughly corresponding to depths of 50 to $100 \mathrm{~km}$. A second negative phase is found at delay times between 14 and $22 \mathrm{~s}$ (Figures $5 \mathrm{~b}$ and $5 \mathrm{~d}$ ) corresponding to depths of 140-200 km. As described above, stacking is done separately for both discontinuities to account for the correct position of the piercing points. We start our analysis with the first $15 \mathrm{~s}$ relative to the onset of the parent $S$ wave. Coordinates of the individual piercing points are calculated with respect to the first negative arrival and data from all stations are stacked in confined regional bins (Figures 5e and 5g).
[12] In the resulting stacks (Figures 5a and 5c) the positive signal generated from the Moho discontinuity occurs rather uniformly at about $4 \mathrm{~s}$ which translates to a conversion depth of $\sim 33 \mathrm{~km}$. In the bins B-D this phase appears slightly earlier pointing to Moho depths $<30 \mathrm{~km}$ beneath the AlbertEdward rift graben. This observation agrees well with depths previously derived from $\mathrm{P}$ receiver functions [Wölbern et al., 2010a]. The negative phase (labeled "MIF") reveals strong variations in delay time: The earliest arrivals are found in the rift valley (bins B-D) with delay times around $6 \mathrm{~s}$. This corresponds to $54 \mathrm{~km}$ depth according to the reference model introduced in Figure 4. Beneath the western rift shoulder (bin A) the discontinuity deepens rapidly over short distance. Here, the signal occurs at $9.3 \mathrm{~s}$ delay time which translates to a depth of about $86 \mathrm{~km}$. In contrast, arrival times east of the rift valley (bins E-H) range between 6.7 and $7.6 \mathrm{~s}$ corresponding to depths of $60-70 \mathrm{~km}$. The discontinuity further deepens toward the Tanzania craton, where it exhibits strong variations in depth. The delay time reaches a maximum of $11.1 \mathrm{~s}$ corresponding to $104 \mathrm{~km}$ (bin O). Resulting depths for all bins are summarized in Figure 5e.

[13] Stacking is repeated in a time window from 10 to $25 \mathrm{~s}$ to account for the correct piercing points related to the deeper discontinuity (Figures $5 \mathrm{~b}$ and 5d). Resulting depths are illustrated in Figure 5f. The signal (labeled "LAB") is less pronounced but shows comparable depth variations as the shallower structure. The interface is shallowest beneath the Rwenzori horst in the Albert-Edward rift segment where arrival times between $14.6 \mathrm{~s}$ and $16.7 \mathrm{~s}$ are determined (bins $\mathrm{A}^{\prime}-\mathrm{C}^{\prime}$ ). This corresponds to depths roughly between 138 and $160 \mathrm{~km}$. The LAB deepens toward the Tanzania craton and adjacent mobile belts to depths ranging between 180 to $210 \mathrm{~km}$ (bins $\mathrm{D}^{\prime}-\mathrm{H}^{\prime}$ ) calculated from delay times of 18.5-21.8 s. Near the rift southeast of Lake Kivu (bin $\mathrm{I}^{\prime}$ ), we also find a deep LAB at a depth of about $205 \mathrm{~km}$. It should be mentioned that a weak positive signal occurs at variable delay times between

Figure 5. Stacked data, depths variations and related piercing points for the two consecutive upper mantle discontinuities. $(a, b)$ These figures show the stacked receiver functions separated in two different time windows in order to ensure the correct piercing point distribution for both of the interfaces. Data have been filtered with a $4 \mathrm{~s}$ lowpass Butterworth filter. Thin lines denote $2 \sigma$ standard deviation intervals as determined from bootstrapping (see text for details). (c, d) These figures show the same traces including interpretations of the observed discontinuities (dotted lines). (e, f) The depth variations of both upper mantle discontinuities are displayed in color-code, respectively. The dots show the average depth in the related bin. Labels correspond to the stacked traces on top. (g, h) These figures show the distributions of individual piercing points (crosses) and the outlines of the defined bins. The dots in light blue denote the locations of contributing stations. The thin dotted lines in Figures 5e to 5h indicate the outline of the Tanzania craton as shown in Figure 1. 
the two negative arrivals. The amplitude is slightly higher in the bins beneath the rift but it also appears beneath the craton. This positive signal points to increasing velocities with depths and could mark the bottom of a low velocity layer.

upper lithosphere

(a)

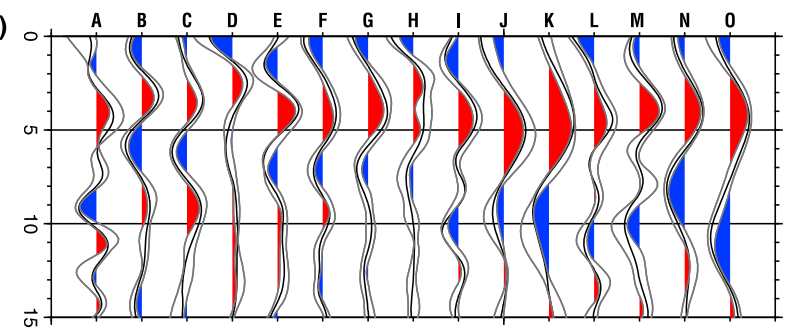

(c)

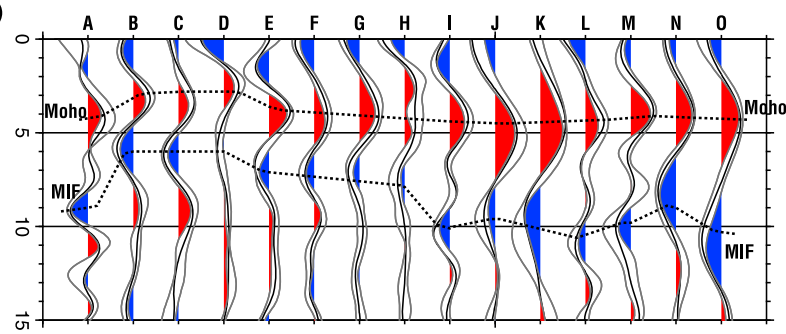

(e)

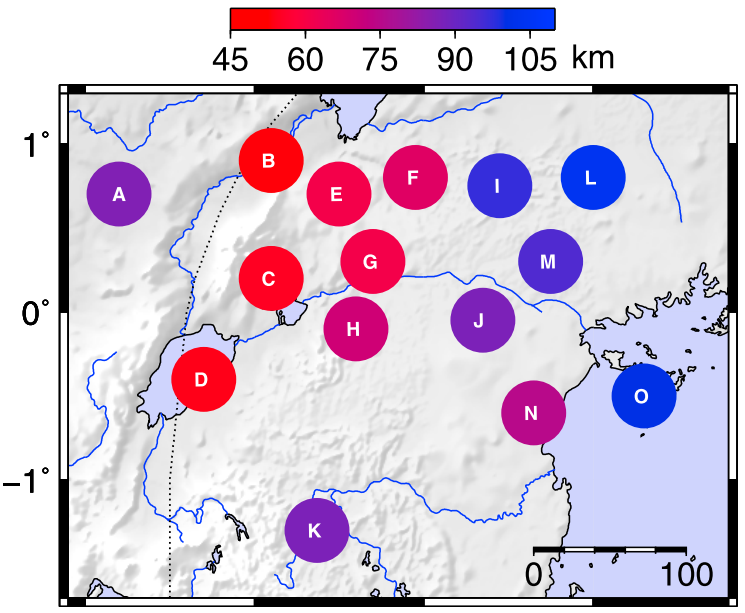

(g)

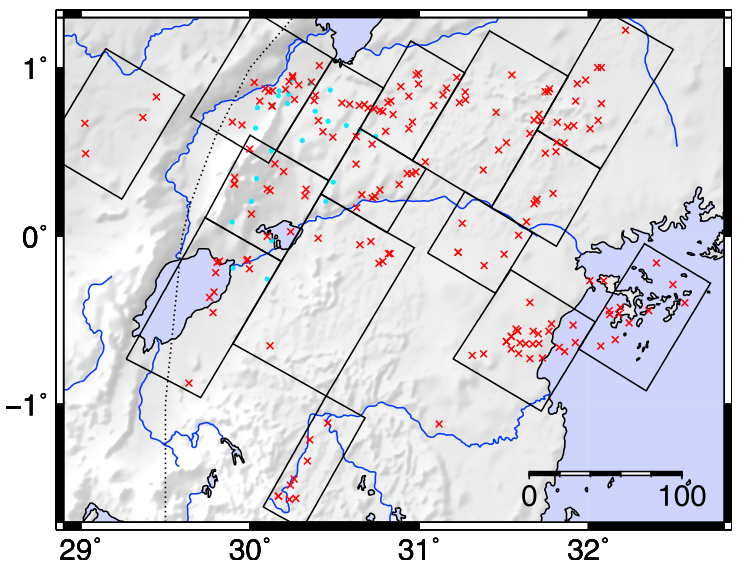

\subsection{Modeling}

[14] We apply forward modeling of $\mathrm{S}$ receiver functions based on the ray theory code of Frederiksen and Bostock [2000] to constrain the velocity distribution of the lithosphere. Synthetics

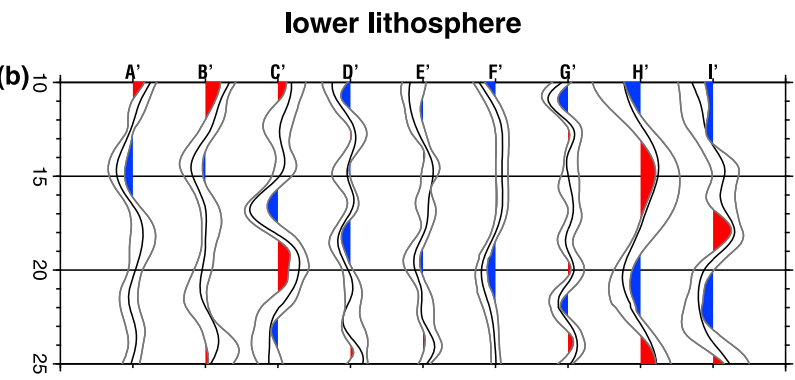

(d)

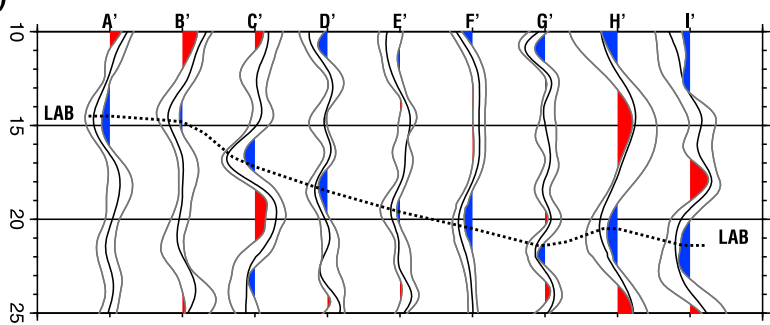

(f)

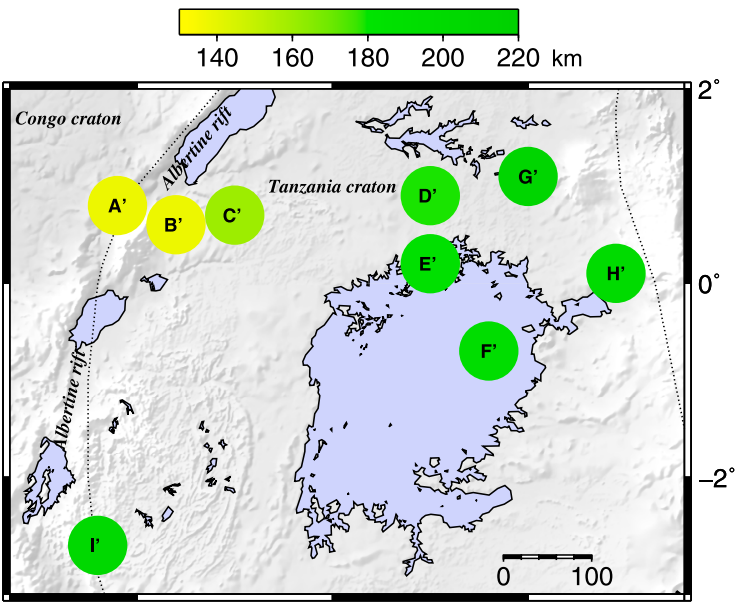

(h)

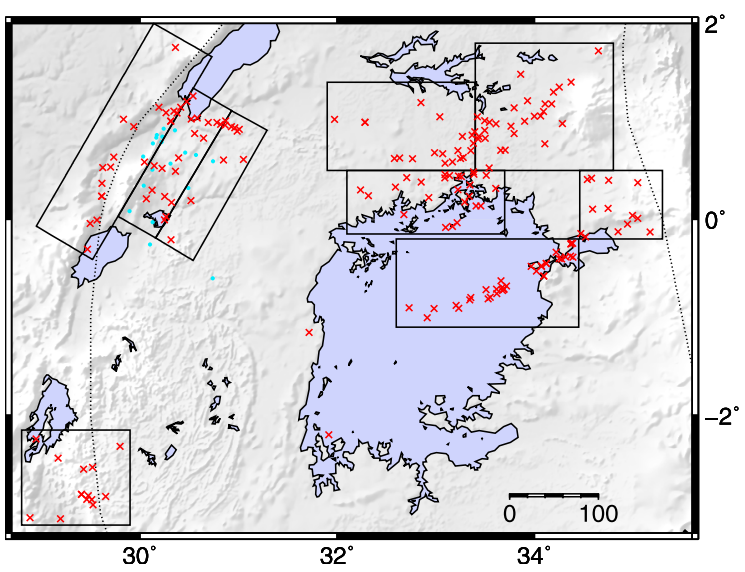

Figure 5 


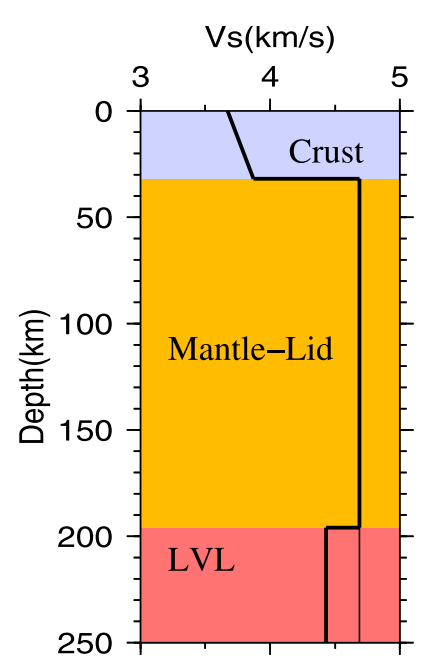

\section{Simple reference models}
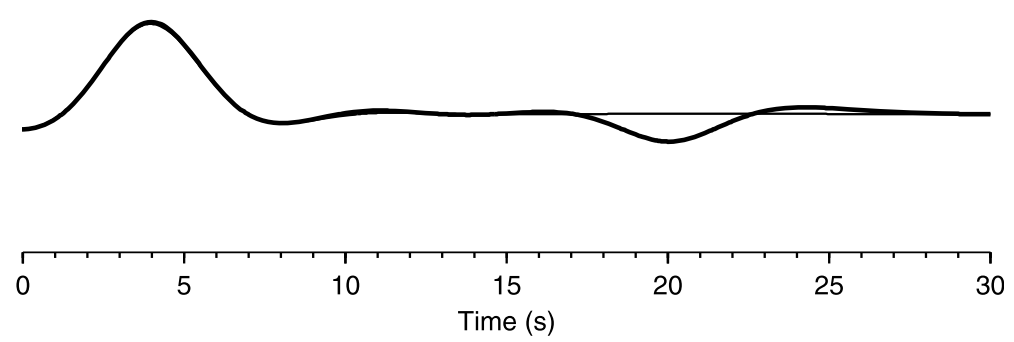

Figure 6. Simple reference models and synthetic receiver functions ( $7 \mathrm{~s}$ lowpass filter) demonstrating the effects of lithospheric discontinuities. The thick line represents cratonic lithosphere including Moho and LAB. The first produces a positive phase at about $4 \mathrm{~s}$. The LAB generates a negative phase at approximately $20 \mathrm{~s}$. This phase is not present in the second model (thin line) which comprises only the Moho discontinuity.

are computed by iteratively fitting the modeled waveform to the observed data utilizing a least squares approach. This procedure has been conducted successfully in previous studies [e.g., Sodoudi et al., 2009]. In order to focus on largescale variations of the lithospheric structure we perform modeling at a lower frequency range using a $7 \mathrm{~s}$ lowpass filter. The starting model consists of a crust with a gradual velocity increase with depth and a simple lithosphere of constant velocity based on the UVI-N74 model [Bram, 1975]. The crustal thickness has been adopted from $\mathrm{P}$ receiver functions [Wölbern et al., 2010a]. For reference we first compute synthetic receiver functions representing ordinary lithosphere (Figure 6). In this model the Moho is represented by a strong positive signal. A supplementary negative signal originates if a lowvelocity layer, such as the asthenosphere, is included. To obtain information about the average shear wave velocity as a function of depth we stack data from two different regions: The first only incorporates traces sampling the assumed LAB in the northern part of the Tanzania craton (corresponding to bin $\mathrm{F}^{\prime}$ in Figures $5 \mathrm{f}$ and $5 \mathrm{~h}$ ) while the second stack contains only traces sampling the discontinuity beneath the Albert and Edward rift segments (corresponding to bin $\mathrm{A}^{\prime}$ and $\mathrm{B}^{\prime}$ in Figures $5 \mathrm{f}$ and $5 \mathrm{~h}$ ). In comparison to the reference model, the observed waveforms clearly exhibit an additional negative phase that demands for a velocity reduction within the lithosphere. The depths of both velocity drops differ significantly between the rift and the craton. For both regions we test a series of models incorporating a simple low- velocity layer constituting the lower part of the lithosphere (LVL 1) and a further velocity drop at the transition to the asthenosphere (LVL 2). While the velocity of all layers is kept fixed for each of the models, the thickness has been varied in intervals of $10 \mathrm{~km}$ (Figure 7). On the basis of the synthetic trace that reveals the best match the model has further been refined in order to optimize the fit to the observed data.

[15] In the cratonic lithosphere a velocity reduction of $11 \%$ has been assumed for LVL 1 and the LAB is expressed in a reduction of $6 \%$. The synthetic waveforms are compared in Figure 7a (top right). The optimized model (bottom) comprises a thickness of $50 \mathrm{~km}$ of LVL 1 with an upper boundary at depth of $78 \mathrm{~km}$. Here, the velocity reduction has been adjusted to $10 \%$ in order to improve the fit to the observed trace. The LAB is located at $195 \mathrm{~km}$ depth with a velocity decrease of $5 \%$. The synthetic receiver functions, however, reveal a significant positive signal between 10 and $15 \mathrm{~s}$ which evolves from the lower boundary of LVL 1. The local maximum occurs in all synthetics regardless of the layer thickness. As this positive signal is observed with much lower amplitude in the data we conclude that a gradual transition has to be taken into account at the bottom of LVL 1. Figure $7 \mathrm{~b}$ displays the results for the Albert-Edward rift segment where a velocity decrease of $19 \%$ is assumed for LVL 1 due to the strong amplitude of the negative signal, whereas a velocity reduction of $7 \%$ has been adopted at the LAB. Velocities have not been changed in 
(a)

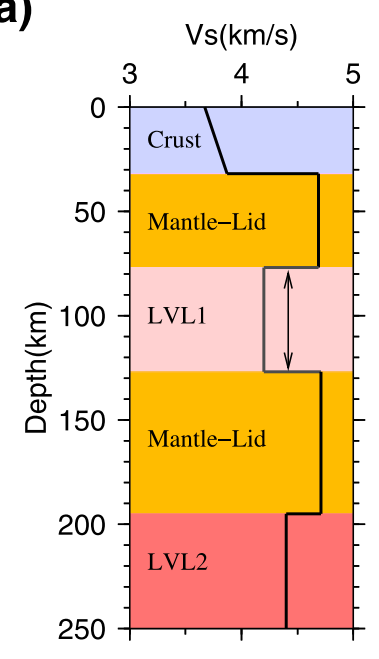

(b)

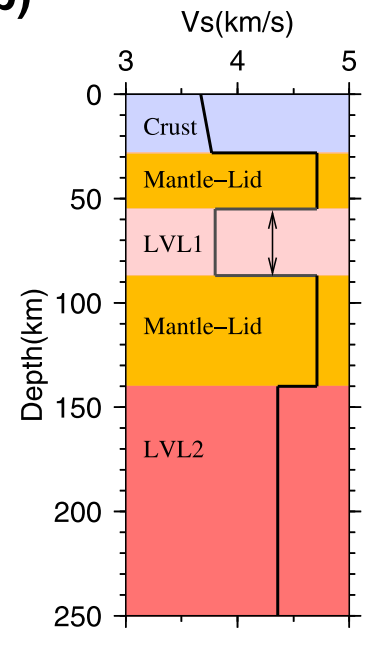

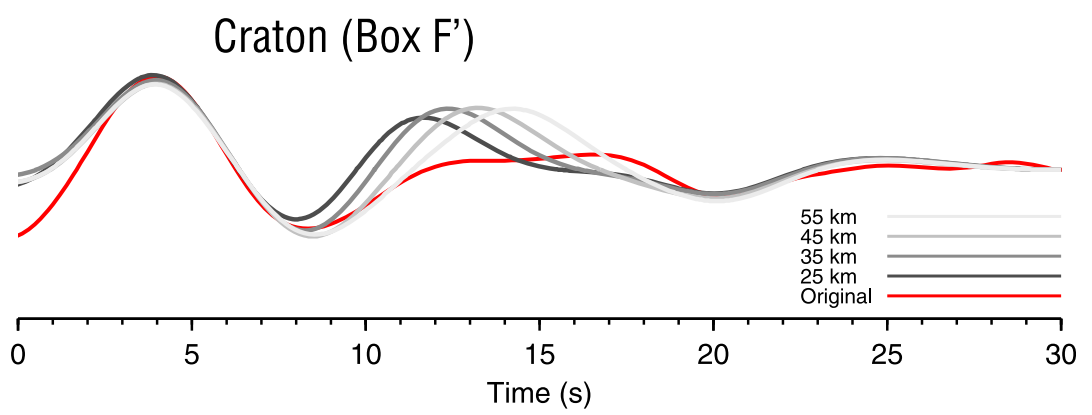

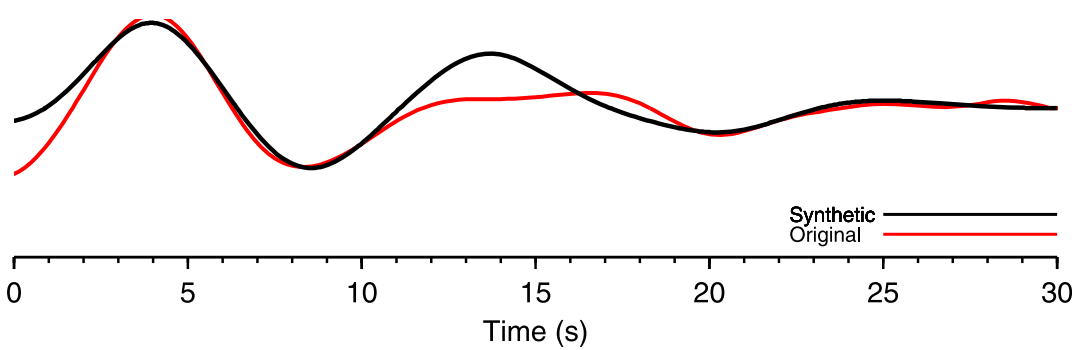

Albertine Rift (Box A' \& B')
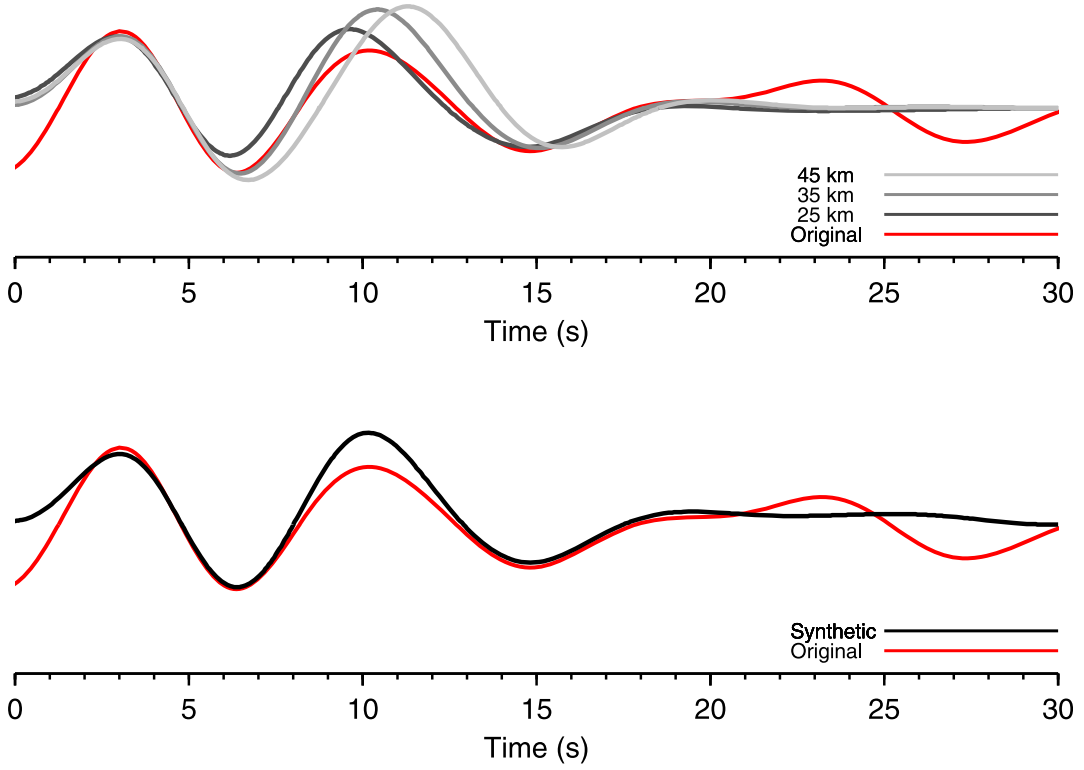

Figure 7. Velocity models comprising a simple low-velocity layer within the lithosphere. $(a, b)$ These figures represent models tested for the Tanzania craton and the Albert and Edward rift segments, respectively. Traces have been filtered with a $7 \mathrm{~s}$ lowpass Butterworth filter in order to focus on the large scale variations with depth. Red lines correspond to observed data, gray and black lines show the modeled waveforms. Low-velocity layers with varying thicknesses have been compared and the related synthetics are shown in shades of gray (upper traces in Figures 7a and 7b). The black lines (lower traces in Figures 7a and 7b) show the synthetic traces that give the best fit to the observed data. Both negative phases can be modeled by a low-velocity layer, however, the positive signal generated at the lower boundary of LVL 1 does not fit to the observed data. 

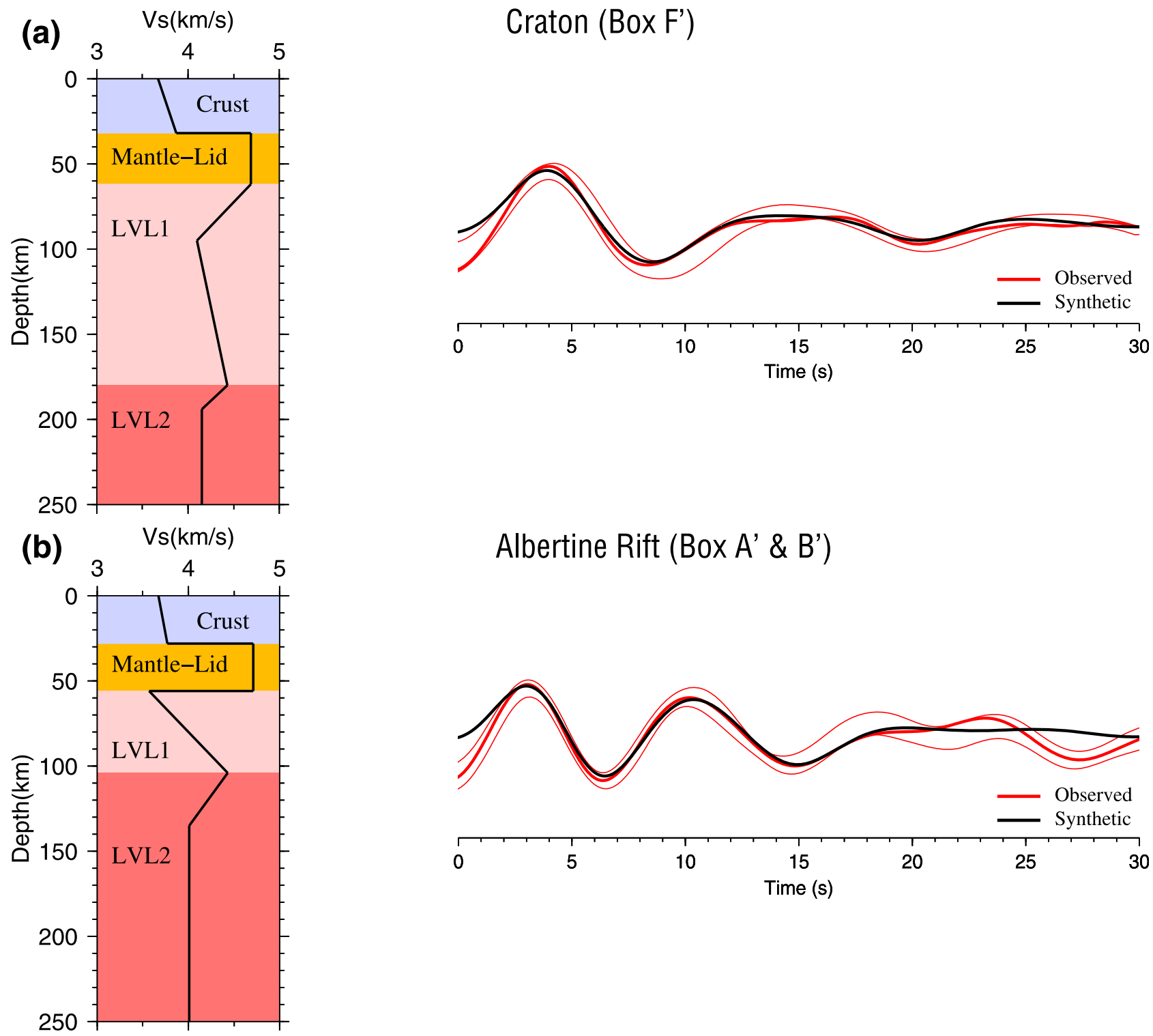

\section{Craton (Box F')}

\section{Albertine Rift (Box A’ \& B’)}

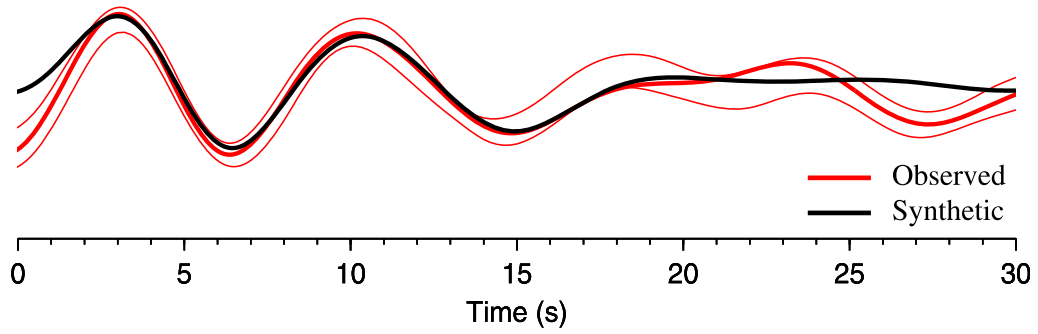

Figure 8. Favored velocity models comprising low-velocity layers confined by gradual transitions. Black lines show the modeled waveforms, red lines correspond to observed data filtered as in Figure 7. The thin red lines show the $2 \sigma$ standard deviation intervals derived from bootstrapping. (a, b) These figures display the optimized models for the Tanzania craton and the Albert-Edward rift, respectively. The best fit for most of the negative phases is obtained with velocity gradients. The first negative arrival in Figure 8b, however, reveals a strong amplitude that is best modeled with a sudden velocity drop. Further signal is observed at $>22 \mathrm{~s}$ which is beyond the scope of our study and has been disregarded in the modeling.

the optimized model (bottom). Here, LVL 1 reveals a thickness of $32 \mathrm{~km}$ with the upper boundary at a depth of $55 \mathrm{~km}$ while the LAB is proposed at $140 \mathrm{~km}$ depth. Again, a strong positive signal emerges at about $10 \mathrm{~s}$ which is generated at the bottom of LVL 1. Again, it is not possible to match the weaker amplitude in the real data with the simple structure assumed in these models. We also expect a velocity gradient here instead of a sudden velocity jump.
[16] We allow for gradual velocity transitions in our models and continue to vary depths and velocities in order to further improve the adaption of the observed receiver functions. The favored models and related synthetics that exhibit the best least squares fit are presented in Figure 8. Beneath the Tanzania craton (Figure 8a) a velocity reduction of about $12 \%$ is required in the lithosphere to match the observed negative phase at $8.4 \mathrm{~s}$. A sufficient fit is obtained with a gradual velocity reduction 

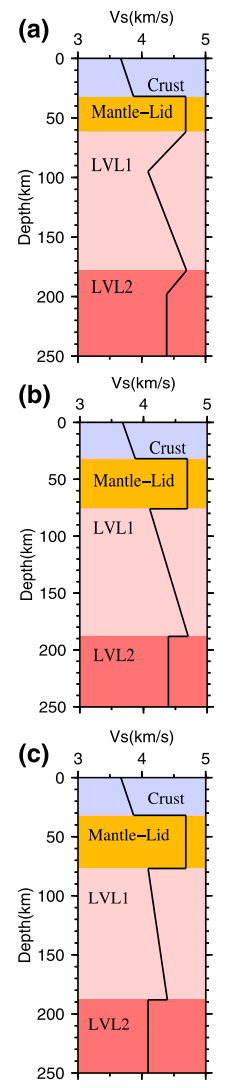
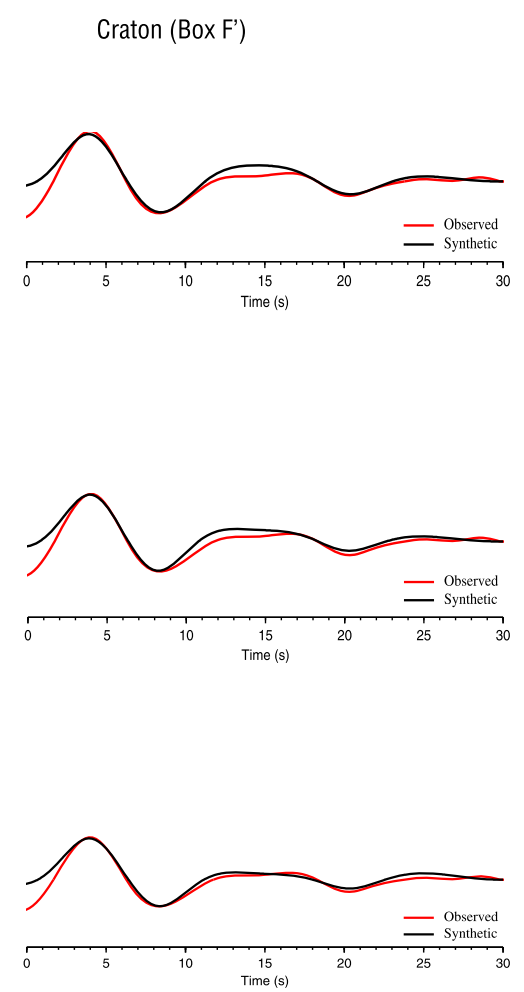

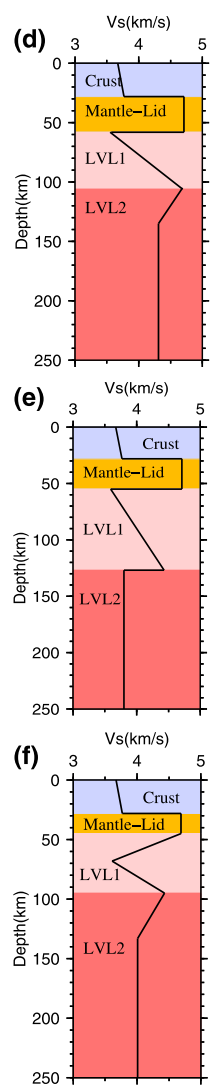

Albertine Rift (Box A' \& B')
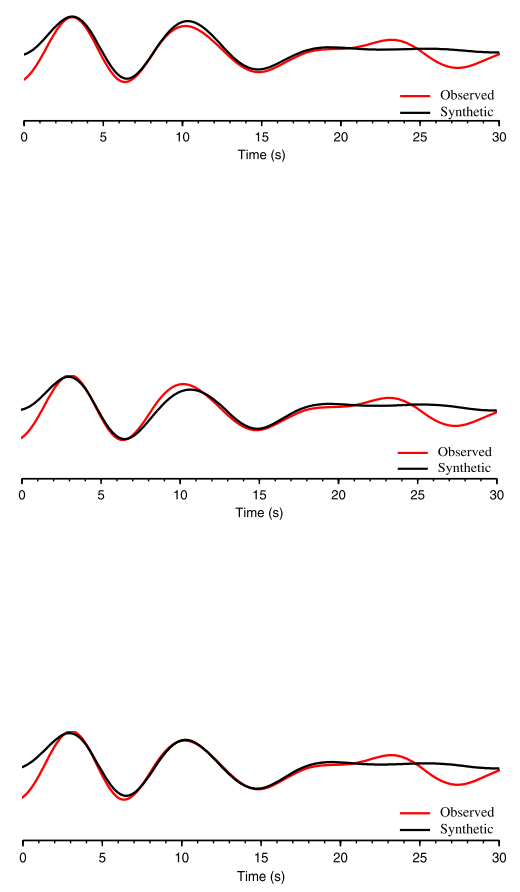

Figure 9. Alternative models including sharp and gradual velocity changes are also capable of explaining the observed waveforms. In either case, there is no way to model the first negative arrival without introducing the LVL 1 in the mid-lithosphere.

between 62 and $95 \mathrm{~km}$. The second discontinuity, interpreted as the LAB, is represented by a further gradual velocity decrease of about $6 \%$ between 180 and $194 \mathrm{~km}$. Both discontinuities shallow toward the rift accompanied by increasing velocity contrasts (Figure 8b). Here, the shallower boundary occurs as a sharp velocity drop of as much as $24 \%$ at a depths of $56 \mathrm{~km}$. Smaller velocity reductions fail to match the observed negative amplitude. At the LAB the shear wave velocity gradually decreases by about $9 \%$ between depths of 104-135 km. However, there are alternative models that also provide sufficient fit to the observed waveforms. We have tested a large number of various models incorporating both sharp and gradual velocity drops. Some examples that satisfactorily match the observed waveforms are presented in Figure 9. In any case, a significant drop of the shear wave velocity within the lithosphere is needed to match the first negative arrival. It is noteworthy that Figure $8 \mathrm{~b}$ shows an additional negative arrival occurring at about $22 \mathrm{~s}$ beneath the rift region. This signal must originate at even greater depth clearly below the lithosphere. Its explanation is, therefore, beyond the scope of this paper and it has not been considered in the forward modeling.

\section{Shear Wave Velocities From Mineralogy}

[17] We independently model the shear wave velocity structure on the basis of mineralogical data obtained for this region. The highly potassic, xenolith-bearing lavas in western Uganda require a mantle source that clearly differs from peridotite and consists of phlogopite and clinopyroxene corresponding to the xenolith compositions found in the same area [Rosenthal et al., 2009; Lloyd et al., 1985]. These mineral assemblages are thought to be primer and very low degree mantle melt that re-crystallized in solid vein networks due to lower surrounding temperatures at lower pressures [Tappe et al., 2006; Foley, 1992] before the recent volcanism started. According to experimentally derived soldidus and liquidus temperatures of peridotite at upper mantle pressures a massive 
crystallization of mantle melt can be presumed as soon the melt migrates to depth shallower than 100-80 km (melt curve summarized in Foley [2008]). Corresponding to the mineralogy of the xenoliths i.e., phlogopite and the absence of amphibole as well as the very potassic chemistry of the associated volcanoes the source region of the volcanoes that is often regarded as the $\mathrm{LAB}$ and that hosts the veins must be at least $100 \mathrm{~km}$ deep from a petrological point of view [Link et al., 2010; Foley et al., 2012]. The very high abundance of clinopyroxene-phlogopite-xenoliths and the lack of peridotite xenoliths in the Toro-Ankole volcanic province are thought to have very intensely infiltrated the lithosphere resulting in massive bodies within the mantle. This is supported by petrological melt experiments done to characterize the source of high potassic volcanics as exposed in this region [Lloyd et al., 1985; Arima and Edgar, 1983].

[18] Once accepting none-peridotitic solid assemblages within the lithosphere that consist mainly of clinopyroxene and phlogopite it has to be questioned if they have an effect on seismic velocities compared to pure fertile or depleted peridotitemantle which is dominated by olivine and contains higher $\mathrm{Mg}$, lower Fe and less Water. Using these petrological assumptions we model the effect of the vein networks on the shear wave velocities $\left(v_{S}\right)$. In order to compute $v_{S}$ for a veined peridotite we calculate the proportion of vein minerals to wallrock minerals depending on the relative amount of veins to wallrock. This results in integrated $v_{S}$ for the considered peridotite mantle with a presumed degree of infiltration. On the basis of the modal mineralogy of $>500$ xenoliths from our own collection we used a modal mineral assemblage of $71 \%$ clinopyroxene and $29 \%$ phlogopite to represent the vein assemblages. This is in accordance with the observations of Lloyd et al. [1985] from the same region. Accessory minerals ( $<5 \%$ in total) such as apatite and titanite are not considered because they do not significantly influence the whole rock $\mathrm{v}_{\mathrm{S}}$ calculations. Pristine mantle lithosphere is represented by published peridotite xenolith data from the Eastern Tanzania craton [Lee and Rudnick, 1999]. The densities of the mineral assemblages are calculated from the sums of the densities of the minerals according to their volume proportions in the rock in respect to the $\mathrm{P} / \mathrm{T}$ conditions based on basic thermodynamics. The shear modulus describing the elastic properties is averaged following Hashin and Shtrikman [1962] and all calculations are done using the database and modified Excel-worksheet from Hacker and Abers
[2004] largely after Bina and Helffrich [1992]. The advantage of this method is its very high sensitivity for chemical and mineralogical changes such as varying $\mathrm{Fe}, \mathrm{Mg}$ or water contents as well as for P/T-variations. The mineral proportions, their element compositions and the calculated shear wave velocities at different $\mathrm{P} / \mathrm{T}$-conditions are summarized in Table 1.

[19] We conducted numerous sensitivity tests varying these parameters and we positively tested our calculations using published experimentally derived seismic velocities on natural mantle samples. Our example simulates the Albert-Edward rift region with $\mathrm{a} \sim 110 \mathrm{~km}$ thick enriched garnetlherzolite lithosphere that is intensely infiltrated by phlogopite- and clinopyroxene bearing veins. At the lithosphere-asthenosphere boundary $15 \%$ veins are presumed which increases toward $95 \%$ to form a massive layer above $80 \mathrm{~km}$ depth. Our calculations are based on a representative rift related geothermes that match enhanced surface heat flows of $\sim 55-60 \mathrm{~mW} / \mathrm{m}^{2}$ [Fadaie and Ranalli, 1990]. The $\mathrm{P} / \mathrm{T}$-profile is constructed by calculating $\mathrm{V}_{\mathrm{S}}$ in $0.2 \mathrm{GPa}$ steps. The calculated $\mathrm{v}_{\mathrm{S}}$ of the phlogopitepyroxenite layer is $3.7 \mathrm{~km} / \mathrm{s}$, i.e., $\sim 20 \%$ slower than in the overlying mantle lid which is represented by spinel-peridotite $(4.66 \mathrm{~km} / \mathrm{s})$. Assuming a decreasing amount of veins with depth the shear velocity increases to $4.38 \mathrm{~km} / \mathrm{s}$ at the LAB at $110 \mathrm{~km}$ depth. Based on petrological observations and assumptions we obtain a seismologically independent shearvelocity profile which we compare to our results derived from S-to-P conversions (Figure 10). Our petrologically derived model focuses on the effect of the solid mantle therefore the liquidus of consisting minerals (the $\mathrm{P} / \mathrm{T}$-conditions under which partial melt is generated) limits the calculations as non-elastic parameters would then dominate the seismic velocities. This implies that at temperatures above $1000^{\circ}$ and pressures above $3.2 \mathrm{GPa}$, where the liquidus of phlogopite-clinopyroxene assemblages is reached, $v_{S}$ cannot be reliably represented by our model. Thus the velocities below about $110 \mathrm{~km}$ in Figure 10 have to be considered with caution. The beginning of partial melting due to exceeding the solidus marks the LAB from the petrological point of view.

\section{Discussion}

[20] S receiver functions have been used to explore the velocity structure beneath the Albert and Edward rift segments and beneath the Tanzania 


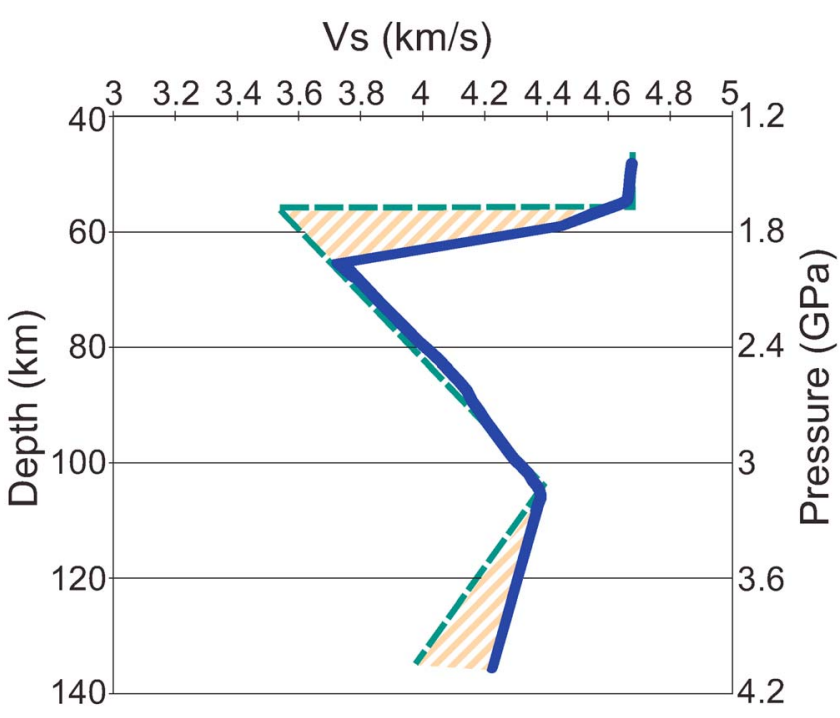

Figure 10. Velocity model for the Albert-Edward rift from mineralogy. The blue line displays shear wave velocities computed on the basis of bulk lithosphere mantle composition and a representative rift-related geotherm. For comparison, the velocity model resulting from the receiver-function modeling (dashed green line) for the same region (Box $\mathrm{A}^{\prime}$ $\& B^{\prime}$ ) is shown (Figure 8b). Despite the good overall agreement there are clear differences in the amplitude of both velocity reductions. This can be explained by partial melting which is anticipated in the context of local volcanism but not considered in the mineralogical modeling.

craton in order to gain a better understanding of the mantle processes in this region. Beneath old platforms and cratons the existence of a midlithospheric discontinuity has been discussed in previous studies whereas the LAB often remains absent or obscured [e.g., Abt et al., 2010; Ford et al., 2010; Savage and Silver, 2008; Fischer et al., 2010; Miller and Eaton, 2010]. Many studies lack direct evidence for a deep LAB because they revealed only one negative signal. The shallow discontinuity has been regarded either as a mid-lithospheric interface or the LAB in view of its depth [e.g., Savage and Silver, 2008; Ford et al., 2010], by comparison with velocity profiles obtained from surface waves [Abt et al., 2010] or by relating receiver-function results to changes in anisotropic properties [Yuan and Romanowicz, 2010]. However, few studies have imaged both discontinuities simultaneously [e.g., Miller and Eaton, 2010]. Our study provides direct evidence for two consecutive velocity reductions within the upper mantle of the Tanzania craton.

[21] As we have summarized in the introduction various mechanisms have been suggested to explain the occurrence of a mid-lithospheric discontinuity in cratonic lithosphere. In a study of the Canadian Shield, e.g., Miller and Eaton [2010] have excluded an origin related to a specific temperature or phase transition due to the strong depth variations of the mid-lithospheric interface. They propose that the discontinuity is caused by material from remnant slabs that have been accreted in the past. The results of our study also reveal strong depth variations of the lithospheric interfaces. These are expected and can be understood in the context of rifting since the discontinuities are shallowest directly beneath the western branch of the EARS. Other authors have alluded to a boundary reflecting compositional changes as a consequence of lithospheric alteration by melt intrusions [e.g., Savage and Silver, 2008; Ford et al., 2010; Abt et al., 2010]. Our data supports a similar mechanism beneath the Tanzania craton and the Albertine rift. The evidence comes from two independent approaches that explain the observed signal in the $S$ receiver functions: the first uses synthetic waveforms obtained from forward modeling and the second computes shear wave velocities from elastic properties as derived from bulk mantle compositions obtained from xenolith data. The upper discontinuity beneath the Tanzania craton and adjacent areas appears to be related to the occurrence of a wideranging vein network. The vein assemblages exhibit an extraordinary petrological composition mainly consisting of pyroxenite and water-bearing phlogopite. As mentioned before lithospheric phlogopite is closely connected to the genesis of highly potassic primitive lavas. Thus phlogopite-rich xenoliths (glimmerites) as well as phlogopite xenocrysts occur 
worldwide in potassium rich lavas such as potassic lamproites [e.g., Prelević et al., 2010; Peterson and LeCheminant, 1993], ultramafic lamprophyres [e.g., Tappe et al., 2006], kamafugites (this study) and in numerous kimberlites [e.g., Gregoire et al., 2002]. A common lithospheric mantle source containing phlogopite has also been reported previously to supply the volcanic provinces of Kivu, Virunga and Toro-Ankole [Furman and Graham, 1999].

[22] Melt infiltration propagating upward from the LAB provides a mechanism that is capable of explaining both the reduced velocities and the occurrence of a mid-lithospheric discontinuity. Furthermore, the formation of aligned vein networks would concurrently explain the patterns of anisotropy that have recently been derived for the Albert-Edward segment of the western branch of the EARS: shear wave splitting results show that anisotropy in this area mainly originates at depths greater than $60 \mathrm{~km}$ with fast axes oriented subparallel to the rift. In contrast, contributions from the crust and the upper lithosphere are negligible [Wölbern et al., 2010b]. Rift-parallel orientations of the fast axes have also been reported from the Ethiopian rift and have been interpreted in terms of aligned melt-filled cracks and dykes located in the upper $70-90 \mathrm{~km}$ of the lithosphere [Ayele et al., 2004; Kendall et al., 2005]. A significant change in azimuthal anisotropy was also found within the cratonic lithosphere of North America which has been reported to correspond with a mid-lithospheric discontinuity [Yuan and Romanowicz, 2010]. Our results point to a similar depth correlation inside the Albert-Edward rift. In view of these findings, we interpret the negative signal in the receiver functions as a result of the transition from the pristine mantle lid to the lower lithosphere which has undergone mineralogical alteration by means of metasomatism. This process has involved melts derived from the asthenosphere below or by partial melting at the base of the lithosphere due to an increased geotherm. Therefore, we have used the term melt-infiltration front (MIF).

[23] The comparative seismological and mineralogical modeling shows that we are able to explain the seismic observation by assuming an increase in the proportion of vein assemblages with decreasing depth. The results of both methods (Figure 10) are in overall agreement, irrespective of deviations in the velocity drops at the MIF between 55 and $66 \mathrm{~km}$ and within the asthenosphere below $105 \mathrm{~km}$. In both cases the velocity decrease is stronger in the receiver-function modeling. These differences can be explained by partial melt existing not only in the asthenosphere but also beneath the mantle lid which would also represent the magma ponding expected to supply the local carbonatitic volcanic fields of the Toro-Ankole Volcanic Province [Boven et al., 1998]. Additional evidence for magmatic processes at this depth comes from recent observations of mantle earthquakes beneath the Ugandan rift shoulder [Lindenfeld and Rümpker, 2011] that are probably related to ascending fluids or volatiles. The strong overlap of the petrological and seismological velocity profiles between 66 and $105 \mathrm{~km}$ depth implies a rather small proportion of melt within this section of the lithosphere. Its negative effect on $\mathrm{v}_{\mathrm{S}}$ would then be within the uncertainty of the two methods. This low degree of partial melt at lower levels of the lithosphere compares well to the petrogenetic models of the highly potassic lavas as described in detail at the beginning of the previous chapter. It is further noteworthy that the western branch exhibits much lower volume volcanism than the eastern branch [Furman, 2007]. Thus, much fewer melt proportions and smaller amounts of magma in the deeper lithosphere are required here.

[24] The deeper discontinuity most likely represents the lithosphere-asthenosphere boundary. Its depth beneath the Tanzania craton agrees well with the range of previously reported thicknesses for the lithosphere in this region [e.g., Ritsema et al., 1998; Weeraratne et al., 2003; Sebai et al., 2006; Fishwick, 2010]. Here, the velocity decreases by about $6 \%$ at the LAB which is consistent with estimates from previous studies related to the cratonic LAB [Rychert and Shearer, 2009; Abt et al., 2010; Fischer et al., 2010]. However, a thermal anomaly is required to stimulate melt ascent and the development of the postulated vein network [Foley, 2008]. Such an anomaly has been postulated previously as, e.g., derived from thinning of the mantle transition zone beneath northern Tanzania [Nyblade et al., 2000] and is supported by a recent study of geochemical data also indicating a broad zone of anomalously hot upper mantle beneath East Africa [Rooney et al., 2012]. The modest temperature anomaly may be related to the fading signature of former plume activity as recently suggested for the Afar rift [Rychert et al., 2012]. We find clear evidence for thinning of the lithosphere beneath the Lake Albert and Lake Edward rift segments (bins $\mathrm{A}^{\prime}$ and $\mathrm{B}^{\prime}$ in Figure $5 \mathrm{f}$ ) by approximately $70 \mathrm{~km}$. No such upwelling of the LAB is observed in the direct vicinity of the Lake Kivu rift segment (bin I' in 


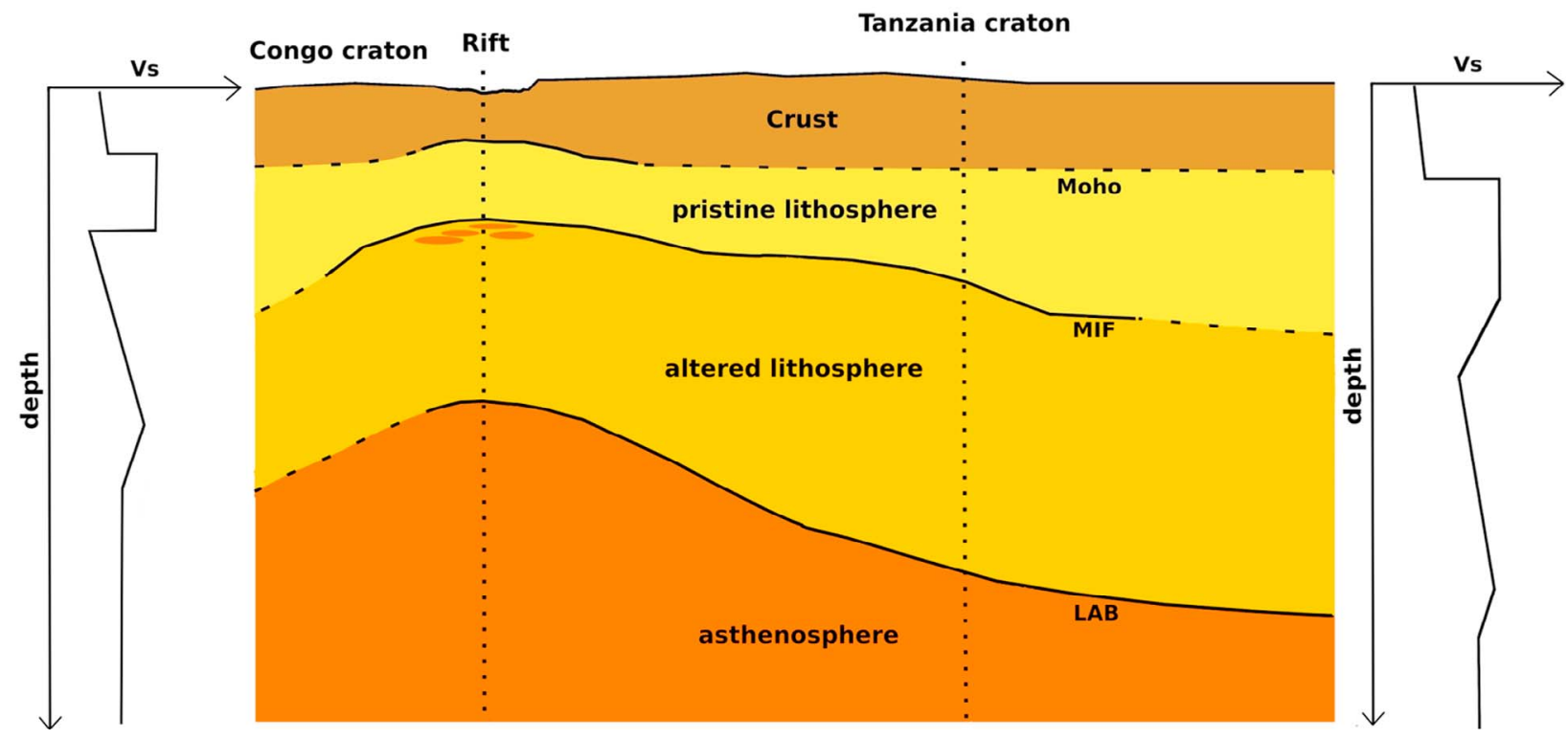

Figure 11. Schematic cross-section of the crust and lithosphere. Different colors illustrate the layered structure of the uppermost mantle. Solid lines denote layer boundaries as derived from S receiver functions. They are extrapolated in areas that are not covered by our data (dashed lines). Our model suggests that asthenospheric melts have intensely infiltrated the mantle-lithosphere through a dense network of crystallized veins. These melts have caused mineralogical alteration. The altered lithosphere terminates at the melt-infiltration front (MIF) which reflects the transition to the pristine upper lithosphere. Dotted lines mark the locations referring to the $\mathrm{S}$ velocity profiles obtained from RF modeling (left) for the rift and (right) for the craton. Red dots below the MIF in the rift zone point to melt accumulations inferred from the sharp velocity drop and supplying local volcanism. Note that the sketch is not to scale.

Figure 5f), where we derive a depth to the LAB of about $200 \mathrm{~km}$ comparable to the interior of the Tanzania craton. However, the diameter of the Fresnel-zone at that depth is about $116 \mathrm{~km}$ (see chapter 3.1) and most of the traces stacked in bin $\mathrm{I}^{\prime}$ sample the LAB east of the rift. Therefore, we assume that bin I' reflects the thickness of the cratonic lithosphere further east rather than that of the Kivu rift. Due to the lack of data sampling the interior of the Kivu rift segment we are not able to draw conclusions about lithospheric thinning here. It has been postulated recently, that the formation of the mountain range may have been induced by large-scale delamination which has removed the entire mantle lithosphere and parts of the lower crust [Wallner and Schmeling, 2010]. As our study provides clear evidence for a lithosphere extending to depths of $<100 \mathrm{~km}$ we conclude that the suggested model is probably not applicable here. Thermal weakening and erosion of the lower lithosphere, however, are anticipated due to the large extent of impregnation. Repeated melt infiltration may have formed deep magmatic incisions which would promote delamination of massive blocks from the base of the lithosphere [Foley, 2008]. This model provides a likely explanation of the anomalously thin lithosphere beneath the western branch of the EARS.

\section{Conclusions}

[25] Receiver functions have been processed from teleseismic S and SKS phases and exhibit two distinct negative phases originating from the upper mantle beneath the Albertine rift and the Tanzania craton. By comparison with synthetic waveforms the arrivals have been clearly identified as being generated at two consecutive discontinuities related to significant velocity reductions. Our findings are summarized in a schematic cross-section in Figure 11. Regional binning has revealed that both discontinuities are shallowest beneath the Albert and Edward rift segments and deepen toward the Tanzania craton. The deeper interface is observed at depths between $135 \mathrm{~km}$ and $210 \mathrm{~km}$ and most likely reflects the lithosphere-asthenosphere boundary. The velocity drop is in the order of $6 \%$ underneath the craton which is in agreement with common estimates. The velocity contrast increases to $9 \%$ in the Albert-Edward rift. The shallower interface ranges between $54 \mathrm{~km}$ and $104 \mathrm{~km}$ which covers the 
same depth range as previously reported for a mid-lithospheric discontinuity. A velocity reduction of $12 \%$ is required within the Tanzania craton increasing to $24 \%$ in the Albertine rift. This indicates that the infiltration of the lower lithosphere is less pronounced underneath the Tanzania craton than beneath the Albert-Edward rift. Based on xenolith samples it has been ascertained that the lithosphere features an extensive vein network that are rich in phlogopite and clinopyroxene. Although, we may not completely exclude other mechanisms, e.g., a change in anisotropic properties, we interpret the mid-lithospheric discontinuity beneath the Tanzania craton and the adjacent western branch of the EARS as the upper boundary of the lower lithosphere that has been mineralogically altered due to metasomatism induced by infiltration of melts derived from the asthenosphere or by partially melting the base of the lithosphere. Therefore, the term melt infiltration front (MIF) is used to describe this interface. Melt infiltration provides a conceivable source of a mid-lithospheric discontinuity in cratonic regions underlain by a broad zone of anomalously hot upper mantle.

\section{Acknowledgments}

[26] This research has been financed by Deutsche Forschungsgemeinschaft (DFG) within the framework of the RiftLink research group (FOR 703). Seismic equipment was provided by the Geophysical Instrument Pool Potsdam (GIPP) and data were archived at the GEOFON data center. We appreciate the support of the Ugandan National Council for Science and Technology (UNCST), the Ugandan Wildlife Authority (UWA) and the Geology Department of the Makerere University in Kampala. Synthetic S receiver functions have been computed using SeisPy - Seismological Python: a Python extension package for seismological analysis by J. Saul, GFZ Potsdam. Additional data from station MBAR were provided by GSN-IRIS/IDA. We thank C. Ebinger and an anonymous reviewer for their thorough and helpful comments that led to significant improvement of the paper.

\section{References}

Abt, D. L., K. M. Fischer, S. W. French, H. A. Ford, H. Yuan, and B. Romanowicz (2010), North America lithospheric discontinuity structure imaged by $P S$ and $S p$ receiver functions, J. Geophys. Res., 115, B09301, doi:10.1029/2009JB006914. Arima, M., and A. D. Edgar (1983), High pressure experimental studies on a katungite and their bearing on the genesis of some potassium-rich magmas of the west branch of the African rift, J. Petrol., 24, 166-187.

Ayele, A., G. Stuart, and J.-M. Kendall (2004), Insights into rifting from shear wave splitting and receiver functions: An example from Ethiopia, Geophys. J. Int., 157, 354-362, doi:10.1111/j.1365-246X.2004.02206.x.
Begg, G. C., et al. (2009), The lithospheric architecture of Africa: Seismic tomography, mantle petrology, and tectonic evolution, Geosphere, 5, 23-50, doi:10.1130/GES00179.1.

Bina, C. R., and G. R. Helffrich (1992), Calculation of elastic properties from thermodynamic equation of state principles, Annu. Rev. Earth Planet. Sci., 20, 527-552, doi:10.1146/ annurev.ea.20.050192.002523.

Boven, A., P. Pasteels, L. E. Punzalan, T. K. Yamba, and J. H. Musisi (1998), Quaternary perpotassic magmatism in Uganda (Toro-Ankole Volcanic Province): Age assessment and significance for magmatic evolution along the East African Rift, J. Afr. Earth Sci., 26, 463-476, doi:10.1016/S0899-5362(98) 00026-8.

Bram, K. (1975), Zum Aufbau der Kruste und des Oberen Mantels im Bereich des Westlichen Graben des Ostafrikanischen Grabensystems und im Östlichen Zaire-Beckens, Geophys. Abh., vol. 4, 65 pp., D. Reimer, Berlin.

Brühl, M., G. J. O. Vermeer, and M. Kiehn (1996), Fresnel zones for broadband data, Geophysics, 61, 600-604.

Calais, E., C. J. Ebinger, C. Hartnady, and J. Nocquet (2006), Kinematics of the East African rift from PGS and earthquake slip vector data, in The Afar Volcanic Province Within the East African Rift System, edited by G. Yirgu et al., Geol. Soc. Spec. Publ., 259, 177-195.

Chakrabarti, R., A. R. Basu, A. P. Santo, D. Tedesco, and O. Vaselli (2009), Isotopic and geochemical evidence for a heterogeneous mantle plume origin of the Virunga volcanics, Western rift, East African Rift system, Chem. Geol., 259, 273-289, doi:10.1016/j.chemgeo.2008.11.010.

Chorowicz, J. (2005), The East African rift system, J. Afr. Earth Sci., 43, 379-410, doi:10.1016/j.jafrearsci.2005.07.019.

De Waele, B., S. P. Johnson, and S. A. Pisarevsky (2008), Paleoproterozoic to Neoproterozoic growth and evolution of the eastern Congo Craton: Its role in the Rodinia puzzle, Precambrian Res., 160, 127-141, doi:10.1016/j.precamres.2007. 04.020 .

Dugda, M. T., A. A. Nyblade, and J. Julia (2007), Thin lithosphere beneath the Ethiopian Plateau revealed by a joint inversion of Rayleigh wave group velocities and receiver functions, J. Geophys. Res., 112, B08305, doi:10.1029/ 2006JB004918.

Eaton, D. W., F. Darbychire, R. L. Evans, H. Grütter, A. G. Jones, and X. Yuan (2009), The elusive lithosphereasthenosphere boundary (LAB) beneath cratons, Lithos, 109, 1-22, doi:10.1016/j.lithos.2008.05.009.

Ebinger, C. J., and N. H. Sleep (1998), Cenozoic magmatism throughout east Africa resulting from impact of a single plume, Nature, 395, 788-791, doi:10.1038/27417.

Ebinger, C. J., T. D. Bechtel, D. W. Forsyth, and C. O. Brown (1989), Effective elastic plate thickness beneath East Africa and Afar plateaus and dynamic compensation of the uplifts, J. Geophys. Res., 94, 2883-2901, doi:10.1029/ JB094iB03p02883.

Fadaie, K., and G. Ranalli (1990), Rheology of the lithosphere in the East-African Rift System, Geophys. J. Int., 102, 445-453, doi:10.1111/j.1365-246X.1990.tb04476.x.

Farra, V., and L. Vinnik (2000), Upper mantle stratification by $\mathrm{P}$ and $\mathrm{S}$ receiver functions, Geophys. J. Int., 141, 699-712, doi:10.1046/j.1365-246x.2000.00118.x.

Fischer, K. M., H. A. Ford, D. L. Abt, and C. A. Rychert (2010), The lithosphere-asthenosphere boundary, Annu. Rev. Earth Planet. Sci., 38, 551-575, doi:10.1146/annurevearth-040809-152438. 
Fishwick, S. (2010), Surface wave tomography: Imaging of the lithosphere-asthenosphere boundary beneath central and south Africa, Lithos, 120, 63-73, doi:10.1016/j.lithos.2010.05.011.

Foley, S. F. (1992), Vein-plus-wall-rock melting mechanisms in the lithosphere and the origin of potassic alkaline magmas, Lithos, 28, 435-453, doi:10.1016/0024-4937(92)90018-T.

Foley, S. F. (2008), Rejuvenation and erosion of the cratonic lithosphere, Nat. Geosci., 1, 503-510, doi:10.1038/ngeo261.

Foley, S. F., K. Link, J. V. Tiberindwa, and E. Barifaijo (2012), Patterns and origin of igneous activity around the Tanzanian craton, J. Afr. Earth Sci., 62, 1-18, doi:10.1016/j.jafrearsci. 2011.10.001

Ford, H. A., K. M. Fischer, D. L. Abt, C. A. Rychert, and L. T. Elkins-Tanton (2010), The lithosphere-asthenosphere boundary and cratonic lithospheric layering beneath Australia from Sp wave imaging, Earth Planet. Sci. Lett., 300, 299-310, doi:10.1016/j.epsl.2010.10.007.

Frederiksen, A. W., and M. G. Bostock (2000), Modelling teleseismic waves in dipping anisotropic structures, Geophys. J. Int., 141, 401-412, doi:10.1046/j.1365-246x.2000.00090.x.

Furman, T. (2007), Geochemistry of East African Rift Basalts: An overview, J. Afr. Earth Sci., 48, 147-160, doi:10.1016/j. jafrearsci.2006.06.009.

Furman, T., and D. Graham (1999), Erosion of lithospheric mantle beneath the East African Rift system: Geochemical evidence from Kivu volcanic province, Lithos, 48, 237-262, doi:10.1016/S0024-4937(99)00031-6.

Green, W. V., U. Achauer, and R. P. Meyer (1991), A threedimensional seismic image of the crust and upper mantle beneath the Kenya rift, Nature, 354, 199-203, doi:10.1038/ $354199 \mathrm{a} 0$.

Gregoire, M., D. R. Bell, and A. P. Le Roux (2002), Mafic and ultramafic xenoliths from the Kaapvaal Craton (South Africa): Trace element evidence for mantle magmatic and metasomatic processes, Geochim. Cosmochim. Acta, 66(15A), A290.

Hacker, B. R., and G. A. Abers (2004), Subduction Factory 3: An Excel worksheet and macro for calculating the densities, seismic wave speeds, and $\mathrm{H}_{2} \mathrm{O}$ contents of minerals and rocks at pressure and temperature, Geochem. Geophys. Geosyst., 5, Q01005, doi:10.1029/2003GC000614.

Hashin, Z., and S. Shtrikman (1962), On some variational principles in anisotropic and nonhomogeneous elasticity, J. Mech. Phys. Solids, 10, 335-342, doi:10.1016/0022-5096(62) 90004-2.

Karato, S., and H. Jung (1998), Water, partial melting and the origin of the seismic low velocity and high attenuation zone in the upper mantle, Earth Planet. Sci. Lett., 157, 193-207, doi:10.1016/S0012-821X(98)00034-X.

Kawakatsu, H., P. Kumar, Y. Takei, M. Shinohara, T. Kanazawa, E. Araki, and K. Suyehiro (2009), Seismic evidence for sharp lithosphere-asthenosphere boundaries of oceanic plates, Science, 324, 499-502.

Kendall, J.-M., G. W. Stuart, C. J. Ebinger, I. D. Bastow, and D. Keir (2005), Magma-Assisted rifting in Ethiopia, Nature, 433, 146-148, doi:10.1038/nature03161.

Kennett, B. L. N., and E. R. Engdahl (1991), Traveltimes for global earthquake location and phase identification, Geophys. J. Int., 105, 429-465, doi:10.1111/j.1365-246X. 1991.tb06724.x.

Kumar, P., et al. (2005), The lithosphere-asthenosphere boundary in the North-West Atlantic region, Earth Planet. Sci. Lett., 236, 249-257, doi:10.1016/j.eps1.2005.05.029.

Lebedev, S., and R. D. Van Der Hilst (2008), Global uppermantle tomography with the automated multimode inversion of surface and $S$-wave forms, Geophys. J. Int., 173, 505-518, doi:10.1111/j.1365-246X.2008.03721.x.

Lee, C. T., and R. Rudnick (1999), Compositionally stratified cratonic lithosphere: Petrology and geochemistry of peridotite xenoliths form the Labait tuff cone, Tanzania, in Proceedings of the 7th International Kimberlite Conference, vol. 2, pp. 503-521, Red Roof Design, Cape Town.

Lekic, V., S. W. French, and K. M. Fischer (2011), Lithospheric thinning beneath rifted regions of Southern California, Science, 334, 783-787, doi:10.1126/science.1208898.

le Roux, A. P., A. Späth, and R. E. Zartman (2001), Lithospheric thickness beneath the southern Kenya Rift: Implications from basalt chemistry, Contrib. Mineral. Petrol., 91, 89-106.

Lindenfeld, M., and G. Rümpker (2011), Detection of mantle earthquakes beneath the East African Rift, Geophys. J. Int., 186, 1-5, doi:10.1111/j.1365-246X.2011.05048.x.

Link, K., D. Koehn, M. G. Bart, J. V. Tiberindwa, E. Barifaijo, K. Aanyu, and S. F. Foley (2010), Continuous cratonic crust between the Congo and Tanzania blocks in western Uganda, Int. J. Earth Sci., 99, 1559-1573, doi:10.1007/s00531-0100548-8.

Lloyd, F. E., M. Arima, and A. D. Edgar (1985), Partial melting of a phlogopite-clinopyroxenite nodule from south-west Uganda: An experimental study of bearing on the origin of highly potassic continental rift volcanics, Contrib. Mineral. Petrol., 91, 321-329, doi:10.1007/BF00374688.

Milesi, J. P., et al. (2004), Géologie et principaux gisements d'Afrique-Carte et SIG à 1:10.000.000, in 20ème Colloque de Géologie Africaine, Bur. de Rech. Geol. et Min., Orléans, France.

Miller, M. S., and D. W. Eaton (2010), Formation of cratonic mantle keels by arc accretion: Evidence from $\mathrm{S}$ receiver functions, Geophys. Res. Lett., 37, L18305, doi:10.1029/ 2010GL044366.

Montelli, R., G. Nolet, F. A. Dahlen, and G. Masters (2006), A catalogue of deep mantle plumes: New results from finitefrequency tomography, Geochem. Geophys. Geosyst., 7, Q11007, doi:10.1029/2006GC001248.

Nyblade, A. A., and R. A. Brazier (2002), Precambrian lithosphere controls on the development of the East African rift system, Geology, 30, 755-758, doi:10.1130/0091-7613(2002) 030<0755:PLCOTD $>2.0$. CO;2

Nyblade, A. A., T. J. Owens, H. Gurrola, J. Ritsema, and C. A. Langston (2000), Seismic evidence for a deep upper mantle thermal anomaly beneath east Africa, Geology, 28, 599-602, doi:10.1130/0091-7613(2000)28<599:SEFADU>2.0.CO;2.

Peterson, T. D., and A. N. LeCheminant (1993), Glimmerite xenoliths in Early Proterozoic ultrapotassic rocks from the Churchill Province, Can. Mineral., 31, 801-819.

Prelević, D., C. Akal, R. L. Romer, and S. F. Foley (2010), Lamproites as indicators of accretion and/or shallow subduction in the assembly of south-western Anatolia, Turkey, Terra Nova, 22, 443-452, doi:10.1111/j.1365-3121.2010.00963.x.

Press, W. H., S. A. Teukolsky, W. T. Vetterling, and B. P. Flannery (1992), Numerical Recipes in FORTRAN, 2nd ed., 686 pp., Cambridge Univ. Press, New York.

Ritsema, J., A. A. Nyblade, T. J. Owens, C. A. Langston, and J. VanDecar (1998), Upper mantle seismic velocity structure beneath Tanzania, east Africa: Implications for the stability of cratonic lithosphere, J. Geophys. Res., 103, 21,201-21,213, doi:10.1029/98JB01274.

Romanowicz, B. (2009), The thickness of tectonic plates, Science, 324, 474-476, doi:10.1126/science.1172879. 
Rooney, T. O., C. Herzberg, and I. D. Bastow (2012), Elevated mantle temperature beneath East Africa, Geology, 40, 27-30, doi:10.1130/G32382.1.

Rosenthal, A., S. F. Foley, D. G. Pearson, G. M. Nowell, and S. Tappe (2009), Petrogenesis of strongly alkaline primitive volcanic rocks at the propagating tip of the western branch of the East African Rift, Earth Planet. Sci. Lett., 284, 236-248, doi:10.1016/j.epsl.2009.04.036.

Rychert, C. A., and P. M. Shearer (2009), A global view of the lithosphere-asthenosphere boundary, Science, 324, 495-498, doi:10.1126/science. 1169754 .

Rychert, C. A., K. M. Fischer, and S. A. Rondenay (2005), Sharp lithosphere-asthenophere boundary imaged beneath eastern North America, Nature, 436, 542-545, doi:10.1038/ nature 03904

Rychert, C. A., P. M. Shearer, and K. M. Fischer (2010), Scattered wave imaging of the lithosphere-asthenosphere boundary, Lithos, 120, 173-185, doi:10.1016/j.lithos.2009.12.006.

Rychert, C. A., J. O. S. Hammond, N. Harmon, J. M. Kendall, D. Keir, C. Ebinger, I. D. Bastow, A. Ayele, M. Belachew, and G. Stuart (2012), Volcanism in the Afar Rift sustained by decompression melting with minimal plume influence, Nat. Geosci., 5, 406-409, doi:10.1038/ngeo1455.

Savage, B., and P. G. Silver (2008), Evidence for a compositional boundary within the lithospheric mantle beneath the Kalahari craton from S receiver functions, Earth Planet. Sci. Lett., 272, 600-609, doi:10.1016/j.epsl.2008.05.026.

Sebai, A., E. Stutzmann, J. P. Montagner, D. Sicilia, and E. Beucler (2006), Anisotropic structure of the African upper mantle from Rayleigh and Love wave tomography, Phys. Earth Planet. Inter., 155, 48-62, doi:10.1016/j.pepi.2005. 09.009 .

Sodoudi, F., X. Yuan, R. Kind, B. Heit, and A. Sadidkhouy (2009), Evidence for a missing crustal root and a thin lithosphere beneath the Central Alborz by receiver function studies,
Geophys. J. Int., 177, 733-742, doi:10.1111/j.1365-246X 2009.04115.x.

Tappe, S., S. F. Foley, G. A. Jenner, L. M. Heaman, B. A. Kjarsgaard, R. L. Romer, A. Stracke, N. Joyce, and J. Hoefs (2006), Genesis of ultramafic lamprophyres and carbonatites at Aillik Bay, Labrador: A consequence of incipient lithospheric thinning the North Atlantic craton, J. Petrol., 47, 1261-1315, doi:10.1093/petrology/eg1008.

Thybo, H., and E. Perchuć (1997), The seismic $8^{\circ}$ discontinuity and partial melting in continental mantle, Science, 275, 1626-1629.

Wallner, H., and H. Schmeling (2010), Rift induced delamination of mantle lithosphere and crustal uplift: A new mechanism for explaining Rwenzori Mountains' extreme elevation?, Int. J. Earth Sci., 99, 1511-1524, doi:10.1007/s00531-010-0521-6.

Weeraratne, D. S., D. W. Forsyth, K. M. Fischer, and A. A. Nyblade (2003), Evidence for an upper mantle plume beneath the Tanzanian craton from Rayleigh wave tomography, J. Geophys. Res., 108(B9), 2427, doi:10.1029/2002JB002273.

Wölbern, I., G. Rümpker, A. Schumann, and A. Muwanga (2010a), Crustal thinning beneath the Rwenzori region, Albertine rift, Uganda, from receiver-function analysis, Int. J. Earth Sci., 99, 1545-1557, doi:10.1007/s00531-0090509-2.

Wölbern, I., B. Homuth, and G. Rümpker (2010b), Lithospheric deformation in the Rwenzori region of the East African Rift from receiver functions and SKS splitting, Abstract DDI11A-1833 presented at 2010 Fall Meeting, AGU, San Francisco, Calif., 13-17 Dec.

Yuan, H., and B. Romanowicz (2010), Lithospheric layering in the North American craton, Nature, 466, 1063-1068, doi:10.1038/nature09332.

Yuan, X., R. Kind, X. Li, and R. Wang (2006), The S receiver functions: Synthetics and data example, Geophys. J. Int., 165, 555-564, doi:10.1111/j.1365-246X.2006.02885.x. 